\title{
Word order and intonation in Georgian
}

\author{
Stavros Skopeteas ${ }^{\mathrm{a}, *}$, Caroline Féry ${ }^{\mathrm{a}}$, Rusudan Asatiani ${ }^{\mathrm{b}}$ \\ ${ }^{a}$ Institute for Linguistics, University of Potsdam, Karl-Liebknecht-Str. 24/25, D-14476 Golm, Germany \\ ${ }^{\mathrm{b}}$ Institute for Oriental Studies, Georgian Academy of Sciences, Acad. G. Tsereteli Str. 3, Tbilisi 0162, Georgia \\ Received 11 April 2007; received in revised form 1 September 2008; accepted 3 September 2008 \\ Available online 28 October 2008
}

\begin{abstract}
Georgian is famous for its word order flexibility: all permutations of constituent order are possible and the choice among them is primarily determined by information structure. In this paper, we show that word order is not the only means to encode information structure in this language, but it is used in combination with sentence prosody. After a preliminary description of the use of prosodic phrasing and intonation for this purpose, we address the question of the interrelation between these two strategies. Based on experimental evidence, we investigate the interaction of focus with word order and prosody, and we conclude that some aspects of word order variation are pragmatically vacuous and can be accommodated in any context if they are realized with an appropriate prosodic structure, while other word order phenomena are quite restrictive and cannot be overridden through prosodic manipulations.
\end{abstract}

(C) 2008 Elsevier B.V. All rights reserved.

Keywords: Georgian; Word order; Intonation; Focus; Acceptability judgments

\section{Introduction}

Georgian is well known for its extreme word order freedom, but less so for a comparable richness in tonal structures. The present paper investigates the relation between word order and intonation, and presents the results of a perception experiment in which both components were varied.

In the next section, the syntactic and intonational issues are introduced. The syntactic issues are based on the abundant literature on Georgian morphosyntax (see section 2.1). The detailed discussions of syntactic issues contrast sharply with the paucity of studies on prosody. Indeed, we could rely on few existing studies, as very little has been published about this subject. The survey of the intonational properties of Georgian found in this paper is based entirely on our own research, and has to be considered as preliminary (see section 2.2). Section 3 of this paper presents an experimental study which addresses the issue of the interrelation of prosody and word order for the encoding of information structure. Section 4 presents and discusses the results, and section 5 concludes.

\footnotetext{
* Corresponding author. Tel.: +49 331 9772968; fax: +49 3319772925.

E-mail addresses: skopetea@rz.uni-potsdam.de (S. Skopeteas), caroline.fery@googlemail.com (C. Féry), r_asatiani@hotmail.com (R. Asatiani).
} 


\section{Background}

\subsection{Word order}

Georgian is characterized as a 'free word order' language: all permutations between major clausal constituents are grammatical (see Aronson, 1982:47; Asatiani, 1982; Boeder, 1989:160; Davitiani, 1973:151; Harris, 1981:22; Hewitt, 1995:528). The fact that the alternative word orders occur with considerable frequency in texts, as already shown in corpus studies (see Vogt, 1971:222; Apridonidze, 1986:136ff.), does not imply that the choice of word order in discourse is random. Aim of this section is to summarize the empirical facts about word order alternation in a theory-neutral way.

\subsubsection{Verb finality}

The following examples illustrate the most frequent orders of clauses involving a transitive verb and two lexically realized arguments, SOV in (1a) and SVO in (1b). Both orders may occur in all-new contexts.

$\begin{array}{lll}\text { క̌arisk'ac-i } & \text { monadire-s } & d a-c^{\prime} r-i-s . \\ \text { soldier-NOM } & \text { hunter-DAT } & \text { PR(FUT)-cut-THM-S.3.SG } \\ \text { క̌arisk'ac-i } & d a-c^{\prime} r-i-s & \text { monadire-s. } \\ \text { soldier-NOM } & \text { PR(FUT)-cut-THM-S.3.SG } & \text { hunter-DAT }\end{array}$

'The soldier will wound the hunter.'

Most authors adopt the view that the basic order is V-final (see Počxua, 1962:122, Aronson, 1982:47; McGinnis, 1997:8; Harris, 2000:141-146; Boeder, 2005:64). The OV order occurs more frequently in the available corpus studies on literary texts (Apridonidze, 1986:136-143; Kvačadze, 1996:258-261; Počxua, 1962:122; Vogt, 1971:222) and equally frequent to the VO orders in a corpus study on fairy tales (Vogt, 1971:222), which suggests that stylistic factors might have an effect on the choice of verb placement as well (Asatiani, 2007b). The syntactic evidence for the assumption of Vfinality is admittedly weak, but all available criteria (e.g., the order in sequences of finite and non-finite verbs in Harris, 2000:145, object placement with coordinated verbs in Skopeteas and Fanselow, in press-b, etc.) suggest a V-final word order.

\subsubsection{Verb fronting}

Assuming that the canonical order is V-final, we should accommodate the empirical fact that the SVO order in (1b) may also occur in pragmatically neutral contexts, as is already observed in the literature (see Anderson, 1984:186; Harris, 1981:22; Hewitt, 1995:528). We assume that these sentences involve an optional head-fronting operation. The assumption of 'optional' V-fronting implies that VO orders are not necessarily the result of a movement operation that targets a position that is associated with a discrete information structural function. V-fronting is a semantically vacuous operation that may be optionally selected in discourse in order to meet preferences on the linearization of the involved constituents (for further discussion, see Skopeteas and Fanselow, in press-b). The exact conditions that determine the choice between $\mathrm{VO}$ and $\mathrm{OV}$ are not yet studied in detail, but the freedom in the alternation between these orders is acknowledged in all studies on Georgian word order. It is important to note that postverbal arguments in clauses involving V-fronting may be narrowly focused (in which case a particular prosodic structure is used, as we show in this paper, see section 3.3).

The freedom in verb placement does not hold for the sentence initial position. Hence, the VSO order illustrated in (2) is a grammatical order, but it occurs in very restricted contexts, e.g., at the beginning of narratives (see Tuite, 1998:41f.). The different status of V-initial orders is reflected in the corpus study of Apridonidze (1986): in sentences with three to six major constituents, the $\mathrm{V}$ is encountered at the sentence initial position only a $3.3 \%$ of the corpus occurrences, while it occurs 53.9\% in the final position and 42.8\% in medial positions (total: 23253 sentences). Hence, we assume that V-initial orders result from a different syntactic operation (of V-movement to a higher clausal position) which is licensed by a restricted subset of contexts. This implies that the optional fronting of the verb takes place within a lower layer of the clause, that does not include the initial position. ${ }^{1}$

\footnotetext{
${ }^{1}$ This observation led Anderson (1984:186) to claim that word order of V-projections is not specified in Georgian, assuming that a V-projection contains the V and its internal arguments. However, it should be noted that V-fronting is optional independently of the constituent that occupies the initial position. Hence, in sentences with a fronted O (e.g., due to object-topicalization), OSV alternates with OVS in the same way SOV alternates with SVO in neutral contexts.
} 
(2)
$d a-\check{c}^{\prime} r-i-s$
క̌arisk'ac-i
monadire-s.
PR(FUT)-cut-THM-S.3.SG
soldier-NOM
hunter-DAT
'The soldier will wound the soldier.'

\subsection{3. $X P_{F O C} V$ adjacency}

Narrow focus has a very robust effect on Georgian word order that is already known in the literature: narrowly focused constituents (as well as interrogative pronouns) appear left adjacent to the finite verb (see Alkhazishvili, 1959; Harris, 1981:14, 1993:1385; Kvačadze, 1996:250; McGinnis, 1997:8 citing Nash, 1995; Asatiani, 2007a; Skopeteas and Fanselow, in press-b). Hence, a subset of the non-V-final clauses in Georgian results from the rule for $\mathrm{XP}_{\mathrm{FOC}} \mathrm{V}$ adjacency, which is a distinct phenomenon from $\mathrm{V}$-fronting. While $\mathrm{V}$-fronting is an optional operation that depends on linearization preferences, narrowly focused constituents induce an obligatory attraction of the finite verb, which renders $\mathrm{XP}_{\mathrm{FOC}} \mathrm{YP} \mathrm{V}$ structures non-acceptable. However, $\mathrm{XP}_{\mathrm{FOC}} \mathrm{V}$ applies only for narrow focus on preverbal arguments. Postverbal arguments may be narrowly focused too, which - if we adopt a hierarchical application of the rules at stake - suggests that optional V-fronting takes place before the operation that establishes $\mathrm{XP}_{\mathrm{FOC}} \mathrm{V}$ adjacency (see further discussion in Skopeteas and Fanselow, in press-b).

\subsubsection{Argument scrambling}

Argument order follows the order $\mathrm{S} \prec \mathrm{O}_{2} \prec \mathrm{O}_{1}\left(\mathrm{O}_{1}=\right.$ direct object; $\mathrm{O}_{2}=$ indirect object) (Amiridze, 2006:52), which reflects the embeddedness of the arguments in verb projections. Deviations from the default order are possible and occur very frequently in discourse. Example (3) illustrates the scrambled version of example (1a).

$$
\begin{array}{lll}
\text { monadire-s } & \text { گ̌arisk'ac-i } & d a-\check{c}^{\prime} r \text { - } i \text {-s. } \\
\text { hunter-DAT } & \text { soldier-NOM } & \text { PR(FUT)-cut-THM-S.3.SG }
\end{array}
$$

'The soldier will wound the hunter.'

The binding possibilities of the non-canonical orders (McGinnis, 1999, 2004; Skopeteas and Fanselow, in press-a) as well as long distance dependencies (Skopeteas and Fanselow, in press-a) show that the reordering of arguments in Georgian has the properties of scrambling. The choice of scrambled orders in discourse may be influenced by general pragmatic preferences such as 'given $\prec$ new', but is not the result of movement to designated information structural positions (see evidence from language production in Asatiani, 2007b; Skopeteas and Fanselow, in press-a).

In sum, word order in Georgian exhibits considerable freedom. The V may be optionally fronted in the layer of the clause below the initial constituent. Clause initial verb placement is possible, but it is the result of another syntactic operation that is licensed by restricted contextual conditions. There is a syntactic operation that requires the adjacency of preverbal narrow focused XPs with the verb. Arguments follow the $\mathrm{S} \prec \mathrm{O}_{2} \prec \mathrm{O}_{1}$ order and deviations from this order are instances of scrambling.

\subsection{Intonational issues}

Some general properties of Georgian intonation are already known through previous studies (Alkhazishvili, 1959; Kiziria, 1987; Tevdoradze, 1978; Zhghenti, 1963). A fundamental issue reported in the literature concerns lexical stress. Authors do not agree on the existence and location of lexical stress, though a majority of researchers assume initial stress; we follow Alkhazishvili (1959), Tevdoradze (1978), and Zhghenti (1963), who claim that pitch accent assignment applies at the post-lexical level. A special prosodic pattern of focused constituents is already mentioned in Alkhazishvili (1959) and Kiziria (1987:56). The first autosegmental account of the association between intonational tones and phonological phrases is Bush (1999); see also Müller (2007), who finds exactly the same pattern for Georgian questions as Bush. Bush provides an insightful analysis of the boundary tones in question sentences, which he analyzes as a complex $\mathrm{L}_{\mathrm{P}} \mathrm{H}_{\mathrm{P}}$, where $\mathrm{L}$ stands for low tone and $\mathrm{H}$ for high tone, and a subscript $\mathrm{P}$ signals the boundary of a prosodic phrase. This complex boundary tone can be followed by 
an additional $\mathrm{L}_{\mathrm{I}}$ or $\mathrm{H}_{\mathrm{I}}$, thus an additional boundary tone for an intonation phrase. One of his examples is reproduced in (4).

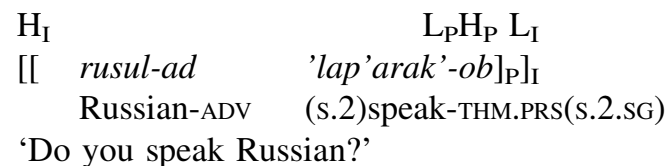

As will become clear below, his analysis of the complex contour found at the end of questions as boundary tones is in line with our own results, as we assume that most of the tonal excursions are to be analyzed as boundary tones.

Jun et al. (2007) give an overview of Georgian intonation based on the speech of one speaker who realized declaratives, wh- questions, yes-no questions, focus sentences and other types of sentences. Their analysis of declarative sentences agrees with ours, but the analysis of sentences containing a focus does not, since they find that a narrow focus is always accompanied by a pitch accent $\left(\mathrm{H}^{*}\right.$ or $\left.\mathrm{L}+\mathrm{H}^{*}\right)$, while we find that a focus can have a flat and low intonation, depending on the place of the sentence it appears.

Given the limits of this paper, we can only outline the main intonational properties of Georgian here, but we report the interested reader to Féry and Skopeteas (2008) for a more detailed account of the phrasing and tonal pattern of declarative sentences containing different focus structures. Our data are described in section 3.3.

\subsubsection{Prosodic phrasing}

First, prosodic phrasing is pervasive and based on syntactic structure. Every constituent forms its own prosodic phrase (p-phrase), with the exception of the verb, which may be integrated into the phrase of an adjacent argument.

\subsubsection{Tonal structure}

Non-final p-phrases have either a rising, or a falling pattern. If they have a rising pattern, a low pitch accent, transcribed as $\mathrm{L}^{*}$, appears very early in the p-phrase. A high tone, which we analyze as a p-phrase boundary tone $\mathrm{H}_{\mathrm{P}}$, appears late in the p-phrase. The rise starts relatively late in the last syllable of every p-phrase. If the contour of a p-phrase is falling, it starts at the level of the preceding $\mathrm{H}_{\mathrm{P}}$, and falls immediately. It is transcribed as $\mathrm{H}^{*} \mathrm{~L}$. In longer words, like in some verbs, a second drop can be located on the second accent of these words. As a rule, the first p-phrase has the clearest intonational contour, and the following p-phrases use only reduced $\mathrm{F}_{0}$ range. The last p-phrase of a sentence is always falling, but in many cases is already so low that no contour is realized at all. We analyze it as $\mathrm{L}^{*} \mathrm{~L}_{\mathrm{I}}$.

\subsubsection{Intonation phrase boundary tones}

The final p-phrase of a declarative sentence ends low, and a low boundary tone ends every declarative sentence (see also Alkhazishvili, 1959; Tevdoradze, 1978; Zhghenti, 1963, who observe that the melodic structure of an affirmative utterance is falling). We postulate a $\mathrm{L}_{\mathrm{I}}$, which is the boundary tone of the intonation phrase (i-phrase).

\subsubsection{Downstep}

An all-new sentence may be uttered in a single i-phrase, and every p-phrase is downstepped relative to the preceding one, which means that the high part of a p-phrase is lower than the high part of the preceding p-phrase. As already mentioned, only the first p-phrase is realized with a full contour and a large range.

\subsubsection{Prosodic prominence}

Prosodic prominence in Georgian is different from what we are used from other languages. Only sentence initially is a narrow focus optionally accompanied by an increase in $\mathrm{F}_{0}$ height. In the sentence-medial and final position, a narrow focus is accompanied by a lower and flatter contour, and by optional deletion of prosodic boundaries. Prosodic prominence is thus replaced by prosodic leveling.

An initial high pitch accent is rather exceptional. In this case, the p-phrase ends with a low boundary tone, $\mathrm{L}_{\mathrm{P}}$.

The next pair of examples illustrates an interesting difference between the realization of a word as part of an all-new sentence or as a narrow focus. The all-new realization is shown in (5). There is a low tone on the first syllable ( $\left.\mathrm{L}^{*}\right)$, and a high tone on the second syllable of bavšvi 'child' $\left(\mathrm{H}_{\mathrm{P}}\right)$. The subject constituent is phrased separately from the verb. 


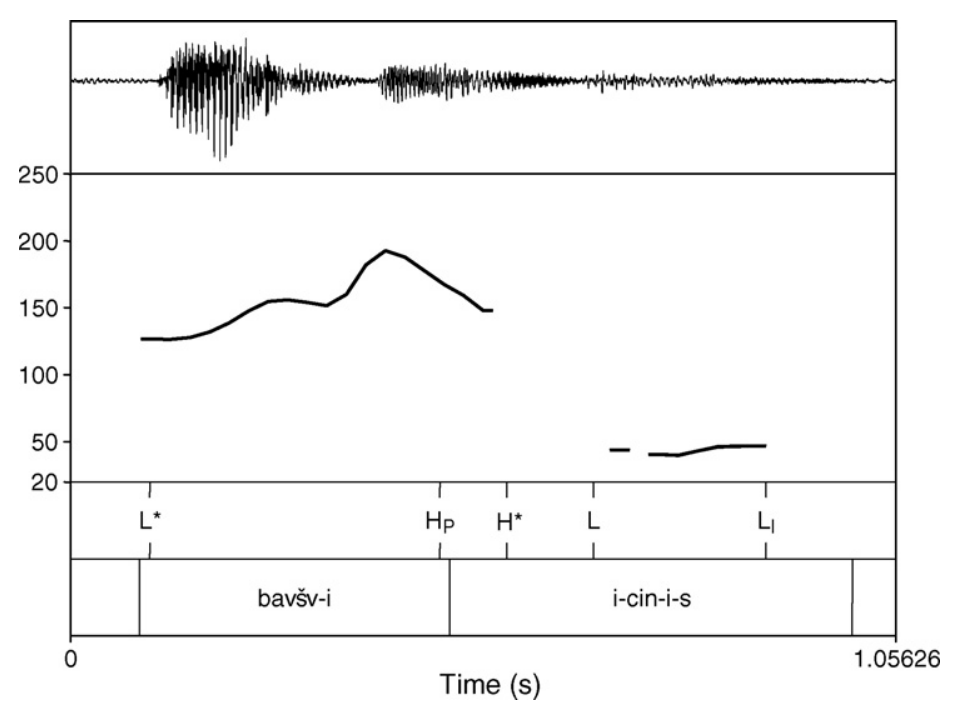

Fig. 1. All-new realization.

The falling pattern on the verb is interpreted as a $\mathrm{H}^{*} \mathrm{~L}$, downstepped relative to the high boundary tone of bav ̌s $v$. The last tone is the low boundary tone of the whole i-phrase (Fig. 1).

(5) \{What is happening?

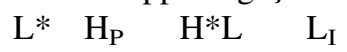

$\left[[b a v \check{s} v-i]_{\mathrm{P}} \quad[i-c i n-i-s]_{\mathrm{P}}\right]_{\mathrm{I}}$

child-NOM PV-laugh-PRS-s.3.SG

'The child is laughing.'

When the subject is narrowly focused, as in (6), there is a rise which already starts on the first syllable; we analyze this as a pitch accent $\mathrm{LH}^{*}$, and this pitch accent is followed by a low boundary tone $\mathrm{L}_{\mathrm{P}}$. The verb has again the pattern $\mathrm{H}^{*} \mathrm{~L}$. In this case, as well, there are two p-phrases, but the tonal structure is different (Fig. 2).

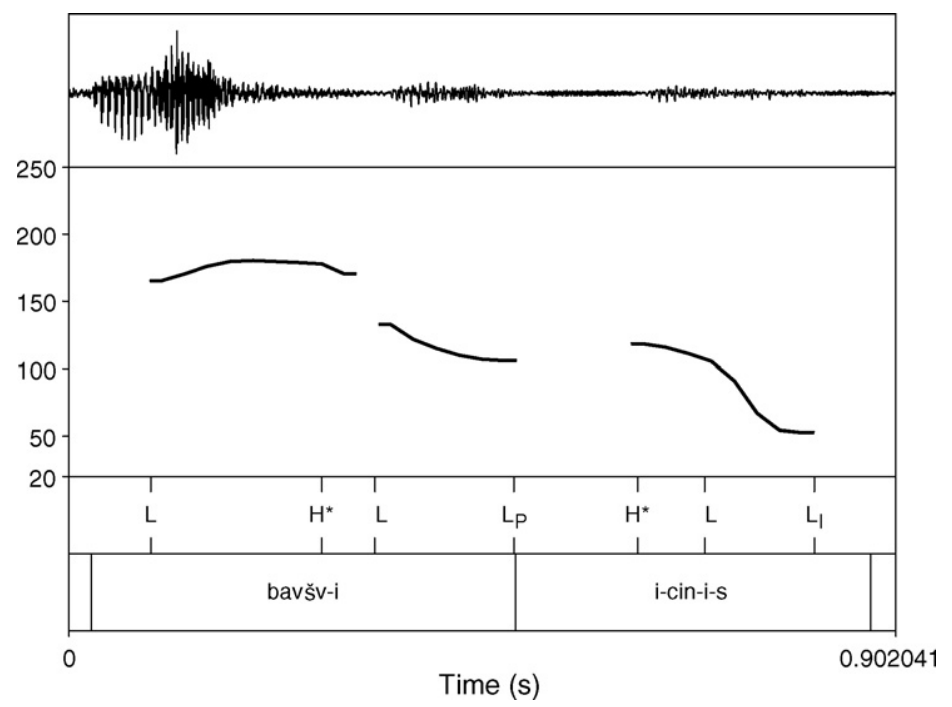

Fig. 2. Narrow focus realization. 
(6) $\quad$ Who is laughing?

$\mathrm{LH}^{*} \mathrm{~L} \mathrm{~L}_{\mathrm{P}} \quad \mathrm{H}^{*} \mathrm{~L} \quad \mathrm{~L}_{\mathrm{I}}$

$\left[[b a v \check{s} v-i]_{\mathrm{P}} \quad[i-c i n-i-s]_{\mathrm{P}}\right]_{\mathrm{I}}$

child-NOM PV-laugh-PRS-S.3.SG

'The child is laughing.'

The contrastive accent has a striking effect: in (6) the word bavšvi has a peak located on the first syllable, whereas in the rising contour in (5), the peak is late in the second syllable. The phonological structure is different. A peak on a word has thus two sources: it may originate from a high pitch accent accompanying a narrow focus or a topic in the initial p-phrase; but most often the peaks in the tonal structure are created by boundary tones.

\section{Experimental study}

The aim of the experimental study described in this section is to gain insights into the interaction between intonation and word order in the encoding of information structure in a language with great freedom in both respects. The method involves manipulation of these two factors and the elicitation of acceptability judgments on context-target sentence pairs by 60 naïve listeners (native speakers of Georgian).

\subsection{Hypotheses}

The aim of the experiment is to shed light on the interaction between intonation and word order in the expression of information structure. Hence, our expectations concerning the influence of these factors depend on the assumptions about the relation between prosodic constraints and syntactic representations. Most accounts on the syntax-prosody interface are based on the idea that prosodic constraints apply on the output of syntactic rules (see Selkirk, 1984; Truckenbrodt, 1999; Büring, 2001; see also discussion in Féry and Samek-Lodovici, 2006). This implies that syntactic well-formedness is independent of prosody, i.e., that prosody applies on the subset of structures that are syntactically well-formed (Golston, 1995). Though this view may be challenged by a range of phenomena that suggest that particular prosodic constraints may outrank syntactic constraints (see Zec and Inkelas, 1990; Harford and Demuth, 1999), it generally holds for the kind of phenomena that are dealt with in our paper that word orders that are syntactically non-well-formed cannot be rendered grammatical through prosodic manipulations.

Turning now to phenomena that relate to the contextual felicity (rather than to the grammaticality) of particular expressions, a different relation between prosody and syntax is suggested by the linguistic data. Empirical studies on intonational languages show that the role of prosody outranks the role of syntax on the felicity conditions of a particular linguistic expression. Keller and Alexopoulou (2001) present evidence from Modern Greek that violations of prosodic constraints have a stronger negative effect on contextual felicity than violations of word order constraints and they conclude that prosodic structures are 'grammaticalized' expressions of information structure, while word orders are not.

The hypothesis put forth in this paper is that two types of word order manipulation have to be distinguished. We assume that some word order possibilities are not uniquely associated with particular information structure; their occurrence in particular contexts is a matter of preference. Word order markedness of this kind may be contextually accommodated by a marked prosodic structure that distributes phonological prominence in the way that fits to the context. Another subset of word order possibilities has strong information structural requirements. We assume that the latter word orders are licit only if the information structural requirements are met; if not, their contextual felicity cannot be 'repaired' by a felicitous prosody. We refer to the former type of word order markedness as resulting from the violation of 'weak' word order constraints and to the latter as resulting from the violation of 'strong' word order constraints.

If we apply this distinction to the observations about Georgian syntax in section 2.1, we may formulate our expectations about the interaction of prosody and word order in this language. We argued with reference to the discussion in the previous literature that argument reordering and V-fronting are optional operations in Georgian. Their occurrence may be influenced by contextual factors, such as the preference for a given $\prec$ new order for scrambling or particular stylistic or prosodic preferences for V-fronting. We hypothesize that sentences involving either operation are marked, but a felicitous prosody may repair the effects of their markedness in any context. On the 
other hand, we argued that V-initial sentences result from a syntactic operation that differs from V-fronting and that this operation is licensed by a very restricted type of contexts. Hence, we assume that, when the contextual requirements are not met, the infelicity of the V-initial structure will not be overridden by a felicitous prosody. Furthermore, we argued that $\mathrm{XP}_{\mathrm{FOC}} \mathrm{V}$ adjacency is obligatory for narrow focus in Georgian. In the same vein, a felicitous prosody is not expected to accommodate violations of this rule. In sum, we assume that scrambling or Vfronting correspond to a weak constraint violation, while $\mathrm{V}$-initiality or a violation of $\mathrm{XP}_{\mathrm{FOC}} \mathrm{V}$ adjacency correspond to a strong constraint violation. Expressions involving violations of the former but not of the latter type can be rendered felicitous when presented with a marked prosodic structure that fits the contextual requirements.

In the context of question/answer pairs, that we examine in our experimental study, we assume that when a marked prosodic realization of the answer meets the requirements of the question, scrambling and $\mathrm{V}$-fronting will not have a substantial effect on the intuition of contextual felicity. V-initiality and violations of the $\mathrm{XP}_{\mathrm{FOC}} \mathrm{V}$ adjacency are expected to have a strong negative effect.

When the prosodic realization of the answer does not fit the question, a strong effect on contextual felicity should result. In this case, the prosodically suboptimal sentences should not be equally rejected, but rather exhibit gradience reflecting their syntactic properties, as it has been already observed in similar experiments of this type (see Keller and Alexopoulou, 2001).

Finally, similar studies on English and German (Gussenhoven, 1983; Alter et al., 2001; Féry and Stoel, 2006) have firmly established that, in these languages, a prenuclear accent is readily accepted, whereas a postnuclear one provokes strong negative reactions. A related question for Georgian is to investigate whether postnuclearity also correlates with deaccenting. We expect that in prosodically non-congruent sentences there will be an influence from the position of the accent: postnuclear accents are expected to have a stronger impact on the acceptability judgments.

(7) Hypotheses

a. Syntactic violations: Strong violations have a stronger impact on acceptability than weak violations.

b. Prosodic violations: A non-felicitous prosody has an additive negative effect to the felicity of syntactic representations.

c. Prosody and syntactic violations: A marked licit prosody only overrides the negative effect of weak word order violations, but cannot have the same effect when strong violations occur.

d. AcCent Placement: Postnuclear non-licit accents have a stronger impact on the acceptability judgments than prenuclear non-licit accents.

\subsection{Experimental design}

\subsubsection{Items and conditions}

In order to test the hypotheses in section 3.1, we designed an experiment based on question/answer pairs. The experiment included three factors: a contextual factor determined by the question (five levels), the word order of the answer (four levels), and the prosodic realization of the answer (two levels). Crossing the levels of all factors gave $5 \times 4 \times 2=40$ experimental conditions. These conditions were implemented in four different sentences, performed in two different tenses each, in order to compensate possible effects of case marking, which is determined by the inflectional properties of the verb in Georgian. In sum, our material contained a total of $40 \times 8=320$ question/answer pairs.

Four different verbs were used in all examined conditions. In order to have four verbs with exactly the same behavior (without differences in use or frequency which could cause variance in the results), we chose four causative verbs, which are shown in (8a-d). In Georgian, causative verbs have the same syntax as ditransitive verbs, licensing a subject (causer), an indirect object (causee), and a direct object (theme). Causee arguments are dealt with as indirect objects in Georgian grammar since they have identical case marking, word order, and agreement properties with recipient constituents.

(a) item 1
dato
nino-s
c'ign-s
c'a-ak'itx-eb-s.
Dato(NOM) Nino-DAT book-DAT PR(FUT)-(IO.3)CAUS.read-THM-S.3.SG
'Dato will cause Nino to read a book.' 
(b) item 2

deda gogo-s c'eril-s da-ac'erin-eb-s.

mother(NOM)girl-DAT letter-DAT PR(FUT)-(IO.3)CAUS.write-THM-S.3.SG

'The mother will cause the daughter to write a letter.'

(c) item 3

kal-i k'ac-eb-s muxa-s mo-ač'revin-eb-s.

woman-NOM man-PL-DAT oak-DAT PR(FUT)-(IO.3)CAUs.cut-THM-s.3.SG

'The woman will cause the men to cut the oak.'

(d) item 4

bavšv-i k'at'a-s tagv-s da-ač'erin-eb-s.

child-NOM cat-DAT mouse-DAT PR(FUT)-(IO.3)CAUS.catch-THM-s.3.sG

'The child will cause the cat to catch the mouse.'

Case marking in Georgian depends on the inflectional properties of the verb. In the verb class that occurs in the stimuli of our experiment, agent constituents bear nominative case in the present and future indicative (direct case marking pattern), while they bear dative case in the perfect tenses (inverse case marking pattern). Theme constituents bear dative case in the direct case marking pattern and nominative case in the inverse pattern. However, case marking does not influence word order or binding asymmetries between agents and patients (see Harris, 1981; Skopeteas et al., 2008). In the inverse case marking pattern, agents are cross-referenced by the same person affixes as goal constituents in the direct pattern, while themes in inverse pattern are cross-referenced by the same affixes as agents in the direct pattern. In order to outbalance a possible impact of case marking in our results, all sentences were used in two different tenses (future indicative and perfect) which license two different case markings on the arguments: causer $=$ nominative, causee $=$ dative, and theme $=$ dative in the future, and causer $=$ dative, causee $=$ postpositional, and theme $=$ nominative in the perfect (compare 9 with the illustrative example for item 1 in example 8 ).

(9) item 1 , perfect tense \& inverse case marking

dato-s nino-s-tvis c'ign-i c'a-uk'itxvinebi-a.

Dato-DAT Nino-GEN-for book-NOM PR-(INVS.3)CAUS.read:PRF-INVO.3

'Dato has (apparently) caused Nino to read a book.'

All four items were produced in four different word orders. The aim of the word order manipulation was to test hypotheses concerning word order markedness. For this purpose, we chose (a) the canonical word order $\mathrm{SO}_{2} \mathrm{O}_{1} \mathrm{~V}$ (Word Order 1, WO1, see (10a)), (b) a word order involving argument reordering, namely $\mathrm{O}_{2} \mathrm{O}_{1} \mathrm{SV}$ (WO2, see (10b)), (c) a word order involving argument reordering (henceforth 'A-reordering') and V-fronting, namely $\mathrm{O}_{1} \mathrm{SVO}_{2}$ (WO3, see (10c)), and (d) a word order involving V-initiality and also reordering of the arguments, namely $\mathrm{VSO}_{1} \mathrm{O}_{2}(\mathrm{WO} 4$, see $10 \mathrm{~d})$. In the sense of the distinction between weak and strong word order violations, that we presented in section 3.1, WO1 does not display any violation, WO2 displays a weak violation (A-reordering), WO3 display two weak violations (A-reordering and $\mathrm{V}$-fronting), and WO4 displays a weak and a strong word order violation (A-reordering and V-initiality). Additionally, WO1-WO3 may display a violation of $\mathrm{XP}_{\mathrm{FOC}} \mathrm{V}$ adjacency depending on context (i.e., whenever the context licenses focus on a preverbal argument that is not adjacent to the verb).
(a) WO1 $\left(\mathrm{SO}_{2} \mathrm{O}_{1} \mathrm{~V}\right)$
dato nino-s c'ign-s c'a-ak'itx-eb-s.
Dato(NOM) Nino-DAT book-DAT PR(FUT)-(IO.3)CAUs.read-THM-s.3.SG
'Dato will cause Nino to read a book.'
(b) $\mathrm{WO} 2\left(\mathrm{O}_{2} \mathrm{O}_{1} \mathrm{SV}\right)$
nino-s c'ign-s dato c'a-ak'itx-eb-s.
(c) $\mathrm{WO} 3\left(\mathrm{O}_{1} \mathrm{SVO}_{2}\right)$
c'ign-s dato c'a-ak'itx-eb-s nino-s.
(d) $\mathrm{WO} 4\left(\mathrm{VSO}_{1} \mathrm{O}_{2}\right)$
c'a-ak'itx-eb-s dato c'ign-s nino-s.

Finally, all four orders were combined with five different context questions. The answer types that are investigated appear in (11), along with an example of a question. (11a) asks for an all-new sentence. (11b-d) ask for a narrow focus 
on an argument: subject, direct object or indirect object. (11e) asks for a multiple focus. ${ }^{2}$ These contexts were chosen in order to allow an examination of the interaction of argument focus with the four word orders. Further contexts that would be of interest are V-focus and VP-focus, which were not included in our experimental design.
(a) All-new pattern (wide focus) answer to 'What is happening?'
(b) Subject focus answer to 'Who will cause Nino to read a book?'
(c) Direct object focus answer to 'What will Dato cause Nino to read?'
(d) Indirect object focus answer to 'Whom will Dato cause to read a book?'
(e) Multiple focus (subject and direct object) answer to 'Who will cause Nino to read what?'

We call 'congruent' a prosodic realization that is felicitous in a particular context, and 'non-congruent' a nonfelicitous one. For each context question, each answer was presented in two different intonation patterns: one realization was congruent to the context, i.e., the prosodically prominent part was the part under question, and the other realization was non-congruent. This is shown in (12) with an example for each case (the exact prosodic realizations of these sentences are discussed in section 3.3). Capitals indicate prosodic prominence.
(a) Question
'Who will cause Nino to read a book?'
(b) WO1 $\left(\underline{\mathrm{SO}}_{2} \mathrm{O}_{1} \mathrm{~V}\right)$, congruent prosody
DATO nino-s c'ign-s c'a-ak'itx-eb-s.
Dato(NOM) Nino-DAT book-DAT PR(FUT)-(IO.3)CAUs.read-THM-s.3.SG
'DATO will cause Nino to read a book.'
(c) WO1 $\left(\mathrm{SO}_{2} \mathrm{O}_{1} \mathrm{~V}\right)$, non-congruent prosody

$\begin{array}{llll}\text { dato } & \text { NINO-S } & \text { c'ign-s } & \text { c'a-ak'itx-eb-s. } \\ \text { Dato(NOM) } & \text { Nino-DAT } & \text { book-DAT } & \text { PR(FUT)-(IO.3)CAUS.read-THM-s.3.SG }\end{array}$
'Dato will cause NINO to read a book.'

In order to keep the material to be judged within comfortable limits, the material used in the perception experiment included for every context and every word order, the prosody hypothesized to be congruent and only one of the prosodies hypothesized to be non-congruent. Which non-congruent answer was used in each case is shown in Table 1. For instance, in the all-new context, and in WO1, the non-congruent answer was the one with a prosodically prominent indirect object in the leftmost top cell of Table 1 (the prosodically prominent argument is underlined).

\subsubsection{Material}

The sentences used in the production experiment were spoken by two native speakers of Georgian, both women in their twenties, with a background in linguistics. The recordings took place in separate sessions and were conducted by the second author in Tbilisi, in September 2005. The first speaker performed the questions and the second speaker performed the answers. The speakers were aware of the goal of the experiment, were instructed to speak as naturally as possible, and were allowed to correct themselves as often as they wanted. The second speaker read the targeted answers in the context of written all-new or constituent questions (depending on experimental condition) and was instructed to put emphasis to the information under question. The performances were recorded on a DAT recorder

\footnotetext{
${ }^{2}$ We do not expect an influence of the word order of the question on the acceptability scorings. The word orders of the questions used in the experiment do not coincide with any of the word orders of the answers, as shown in following:

(a) All-new question: SV?

(b) Subject focus question: $\quad \mathrm{SVO}_{2} \mathrm{O}_{1}$ ?

(c) Direct object focus question: $\mathrm{O}_{1} \mathrm{VSO}_{2}$ ?

(d) Indirect object focus question: $\mathrm{O}_{2} \mathrm{VSO}_{1}$ ?

(e) Multiple constituent question: $\mathrm{SVO}_{2} \mathrm{O}_{1}$ ?
} 
Table 1

Prosodically prominent constituents in non-congruent answers

\begin{tabular}{|c|c|c|c|c|}
\hline & WO1 & WO2 & WO3 & WO4 \\
\hline All-new question & $\mathrm{SO}_{2} \mathrm{O}_{1} \mathrm{~V}$ & $\underline{\mathrm{O}}_{2} \mathrm{O}_{1} \mathrm{SV}$ & $\mathrm{O}_{1} \mathrm{SVO}_{2}$ & $\mathrm{VSO}_{1} \underline{\mathrm{O}}_{2}$ \\
\hline Subject question & $\mathrm{S} \underline{\mathrm{O}}_{2} \mathrm{O}_{1} \mathrm{~V}$ & $\underline{\mathrm{O}}_{2} \mathrm{O}_{1} \mathrm{SV}$ & $\underline{\mathrm{O}}_{1} \mathrm{SVO}_{2}$ & $\operatorname{VSO}_{1} \overline{\mathrm{O}}_{2}$ \\
\hline Direct object question & $\underline{\mathrm{S}} \mathrm{O}_{2} \mathrm{O}_{1} \mathrm{~V}$ & $\underline{\mathrm{O}}_{2} \mathrm{O}_{1} \mathrm{SV}$ & $\overline{\mathrm{O}}_{1} \underline{\mathrm{S} V O} \mathrm{O}_{2}$ & $\mathrm{VSO}_{1} \underline{\mathrm{O}}_{2}$ \\
\hline Indirect object question & $\mathrm{SO}_{2} \underline{\mathrm{O}}_{1} \mathrm{~V}$ & $\mathrm{O}_{2} \mathrm{O}_{1} \underline{\mathrm{SV}}$ & $\underline{\mathrm{O}}_{1} \mathrm{SVO}_{2}$ & $\mathrm{VS}_{\underline{S}} \mathrm{O}_{1} \mathrm{O}_{2}$ \\
\hline Multiple constituent question & $\mathrm{SO}_{2} \overline{\mathrm{O}}_{1} \mathrm{~V}$ & $\underline{\mathrm{O}}_{2} \mathrm{O}_{1} \mathrm{SV}$ & $\mathrm{O}_{1} \mathrm{SVO}_{2}$ & $\mathrm{VSO}_{1} \underline{\mathrm{O}}_{2}$ \\
\hline
\end{tabular}

(SONY 100). Later on, some informal naturalness checks of the recordings of both speakers were made with other Georgian speakers, one of these being the third author. All listeners confirmed that the speakers were very natural.

\subsubsection{Method}

Question/answer pairs were presented acoustically to listeners who gave judgments on a scale from 1 to 5 about their appropriateness: 1 was the best, 5 the worst, and 2-4 were intermediate levels. The participants were instructed to listen carefully to the question/answer pairs and to give a higher score if the answer sounded natural and made sense as an answer to the preceding question. The written instructions made clear that the ratings should not reflect their intuitions about "correct" Georgian, but rather the speaker had to consider whether they thought that the question/ answer pair could occur in a natural conversation. The use of scalar judgments is based on the assumption that native speakers perceive different degrees of appropriateness of several structures in context (see Cowart, 1997, for methodological aspects, as well as Keller and Alexopoulou, 2001, for a similar experiment on Greek, and Féry and Stoel, 2006, for some results on the perception of similar pairs in German).

Sixty (male and female) native speakers of Georgian, all students at the University of Tbilisi, participated to the experiment, which was conducted by the first and third authors and two Georgian student assistants. The experiment took place at the University of Tbilisi and was performed in two days. The informants were paid for their participation.

The 320 pairs were divided into four subsets, and each informant was asked to rate only one set. As a result, every person had to give a rating for 80 question/answer pairs, which contained each experimental condition twice. The subsets of sentences were rated by 15 persons each. The question/answer pairs had been implemented in a DMDX presentation and were automatically randomized for each subject. The duration of the entire experimental session was approximately $20 \mathrm{~min}$. Subjects first went through a training session containing five question/answer pairs, and when they felt confident with the task, they went on to the actual experiment.

\subsection{Intonation pattern of the stimuli}

The first sentence illustrates the tonal contours of the material used in the experiment. The speaker was very consistent in her productions of the four sentences, so that the illustrations are representative for the whole material. To keep the discussion short, one example for each focus pattern is given here, that shows the main characteristics of the tonal patterns. ${ }^{3}$

A special feature of Georgian intonation that we have already mentioned in section 2.2 is the clear phrasing in each realization. A constituent is generally phrased individually and realized with the tonal excursions typical for a pphrase, with the exception of the verb. In our data, the verb is nearly always included in the same p-phrase as an adjacent argument. In general, it is the preceding argument, like the direct object in WO1 $\left(\mathrm{SO}_{2} \mathrm{O}_{1} \mathrm{~V}\right)$. When the verb is sentence initial, there is no preceding argument and the verb is included in the phrase of the following argument, which is the subject in $\mathrm{WO} 4\left(\mathrm{VSO}_{1} \mathrm{O}_{2}\right)$.

As for the tonal contour, recall that non-final phrases have two possible contours: a rising contour, analyzed as $\mathrm{L}^{*} \mathrm{H}_{\mathrm{P}}$, or a falling one, analyzed as $\mathrm{H}^{*} \mathrm{LL}_{\mathrm{P}}$ (see section 2.2). We also mentioned the fact that the final p-phrase is often so low that no contour is realized. In this case, we assume that only the final boundary tone $\left(\mathrm{L}_{\mathrm{P}}\right.$ or $\left.\mathrm{L}_{\mathrm{I}}\right)$ is assigned to the p-phrase. Another variation concerning the falling pattern is that the high pitch accent $\mathrm{H}^{*}$ may be preceded by a rise, that we analyze as a leading tone $\mathrm{L}$ coming before the high pitch accent. In this case the contour of the p-phrase is $\mathrm{LH}^{*} \mathrm{~L}_{\mathrm{P} / \mathrm{I}}$.

\footnotetext{
${ }^{3}$ According to the intuition of the third author, a native speaker of Georgian, there is always a lexical stress on the first syllable of each word in our examples, and the verbs can also have a secondary stress on the third syllable. As in our sentences the verb had only little prominence (because the sentences were elicited either in 'all-new' contexts or in contexts inducing argument focus), there is no tonal reflex of secondary stress in the pitch tracks.
} 


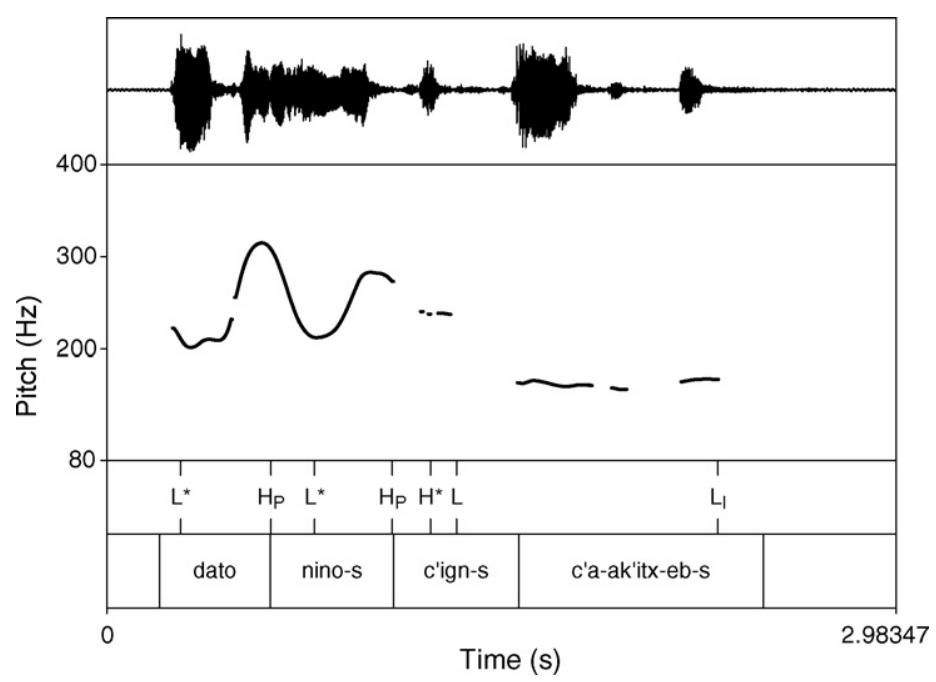

Fig. 3. Item 1 in $\mathrm{WO} 1\left(\mathrm{SO}_{2} \mathrm{O}_{1} \mathrm{~V}\right)$ : all-new context.

In the all-new sentences, an illustration of which is given in (13a) and Fig. 3, the non-final p-phrases were realized by our speaker with the default contour $\mathrm{L}^{*} \mathrm{H}_{\mathrm{P}}$. We found a single counterexample: in WO3 $\left(\mathrm{O}_{1} \mathrm{SVO}_{2}\right)$, the direct object carried a falling contour, which may reflect a different spontaneous interpretation of the information structure of the sentence, due to the marked word order.

The p-phrase containing the verb, the last one in (13a), often started with a high tone followed by an immediate fall. The final boundary tone is low as it is the last p-phrase in the sentence.

An additional feature of Georgian intonation is visible from the pitch track in Fig. 3: downstep of the $\mathrm{H}$ tones of each p-phrase in an i-phrase, expressing cohesion between the p-phrases. Each $\mathrm{H}$ tone is lower than the preceding one.

(a) All-new congruent pattern
$\mathrm{L}^{*} \mathrm{H}_{\mathrm{P}}$
$\mathrm{L}^{*} \mathrm{H}_{\mathrm{P}}$
$\mathrm{H} * \mathrm{~L}$
$\mathrm{L}_{\mathrm{I}}$

$\left[[\text { dato }]_{\mathrm{P}} \quad[\text { nino-s }]_{\mathrm{P}} \quad\left[c^{\prime} \text { ign-s } c^{\prime} a-a k^{\prime} i t x-e b-s\right]_{\mathrm{P}}\right]_{\mathrm{I}}$

Dato(NOM) Nino-DAT book-DAT PR(FUT)-(IO.3)CAUS.read-THM-S.3.SG

(13b) is a sentence with narrow focus on the subject. The accompanying pitch track in Fig. 4 shows that the focused p-phrase may be realized with a falling contour (though this correlation is not obligatory). In this sentence also, we find

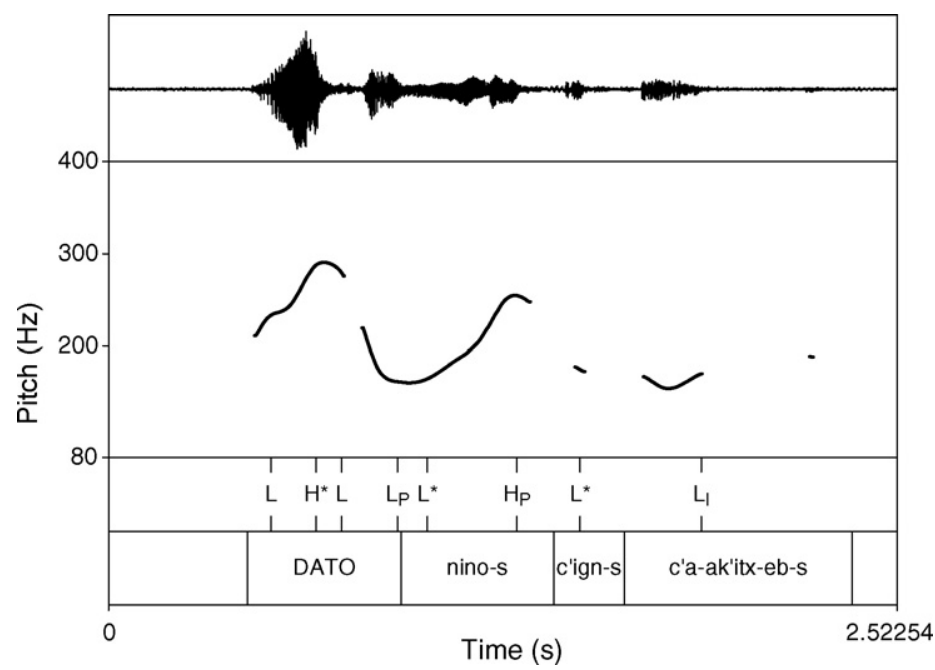

Fig. 4. Item 1 in $\mathrm{WO} 1\left(\mathrm{SO}_{2} \mathrm{O}_{1} \mathrm{~V}\right)$ : subject focus. 


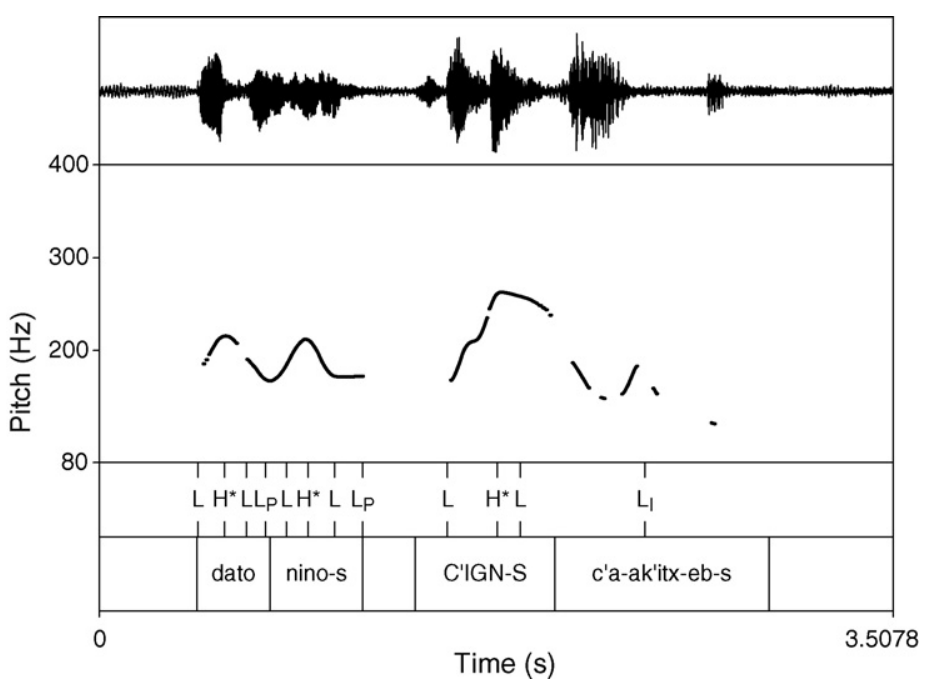

Fig. 5. Item 1 in $\mathrm{WO} 1\left(\mathrm{SO}_{2} \mathrm{O}_{1} \mathrm{~V}\right)$ : direct object focus.

downstep of the $\mathrm{H}$ tones. The last p-phrase already starts at a low level and remains low and flat throughout. This is an instance of the low p-phrase that we analyze as $\mathrm{L}^{*} \mathrm{~L}_{\mathrm{I}}$.

(b) Subject focus congruent pattern
$\mathrm{LH}^{*} \mathrm{~L} \mathrm{~L}_{\mathrm{P}} \mathrm{L}^{*} \quad \mathrm{H}_{\mathrm{P}} \mathrm{L}^{*}$
$\mathrm{L}_{\mathrm{I}}$

$\left[[D A T O]_{\mathrm{P}} \quad[\text { nino-s }]_{\mathrm{P}}\left[c^{\prime} \text { ign-s c'a-ak'itx-eb-s}\right]_{\mathrm{P}}\right]_{\mathrm{I}}$

The pitch track in Fig. 5 illustrates a rather special contour. Both unfocused arguments, the subject and the indirect object, as well as the focused argument, the direct object, have a pitch accent, but the one on the direct object is much higher than the others.

(c) Direct object congruent pattern

$\mathrm{LH}^{*} \mathrm{~L} \mathrm{~L}_{\mathrm{P}} \mathrm{LH}^{*} \mathrm{~L} \mathrm{~L}_{\mathrm{P}} \mathrm{LH}^{*} \mathrm{~L} \quad \mathrm{~L}_{\mathrm{I}}$

$\left[[\text { dato }]_{\mathrm{P}} \quad[\text { nino-s }]_{\mathrm{P}} \quad\left[c^{\prime} I G N-S \text { c'a-ak'itx-eb-s }\right]_{\mathrm{P}}\right]_{\mathrm{I}}$

In Fig. 6, with focus on the indirect object, the prefocal subject does not exhibit the default contour $L^{*} H_{P}$, but has a low contour $\mathrm{L}^{*} \mathrm{~L}_{\mathrm{P}}$. The focused argument, by contrast, has an unmarked $\mathrm{L}^{*} \mathrm{H}_{\mathrm{P}}$ contour. Such sentences occurred only rarely in our data.

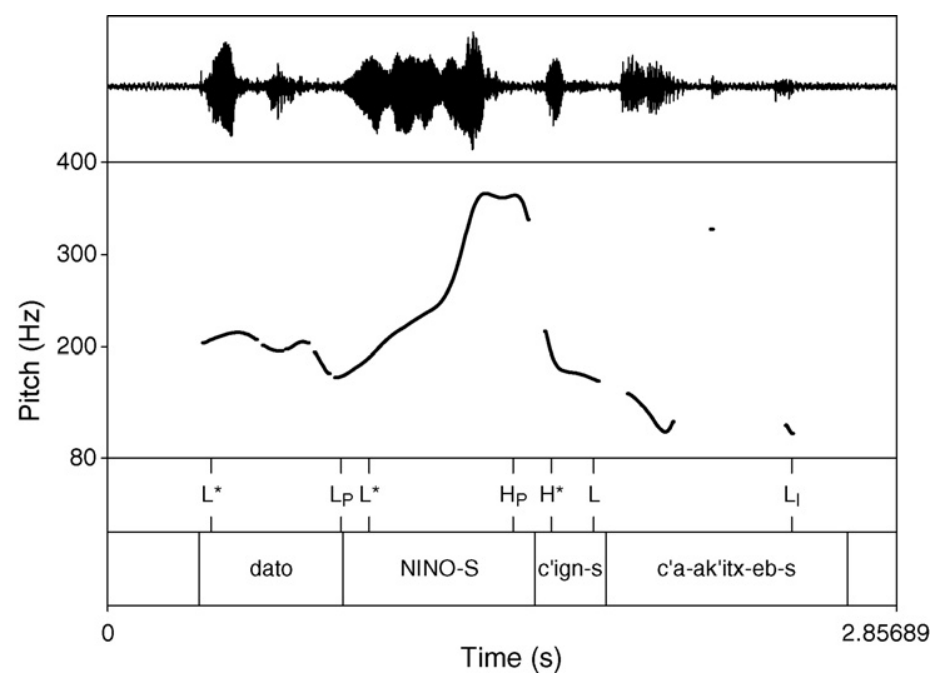

Fig. 6. Item 1 in $\mathrm{WO} 1\left(\mathrm{SO}_{2} \mathrm{O}_{1} \mathrm{~V}\right)$ : indirect object focus. 


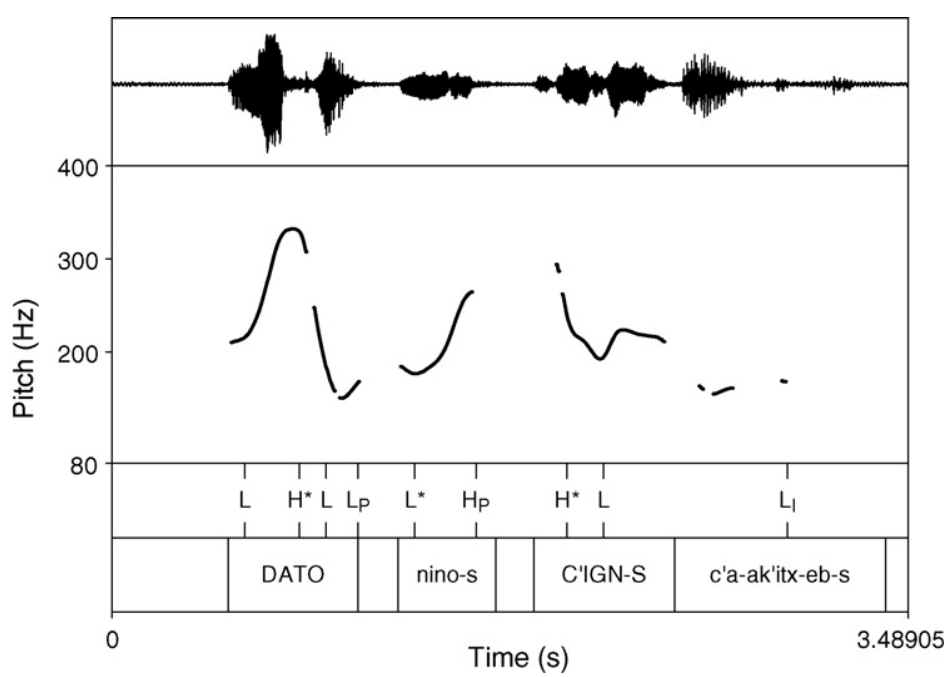

Fig. 7. Item 1 in $\mathrm{WO} 1\left(\mathrm{SO}_{2} \mathrm{O}_{1} \mathrm{~V}\right)$ : multiple focus.

(d) Indirect object congruent pattern
$\mathrm{L}^{*} \mathrm{~L}_{\mathrm{P}} \mathrm{L}^{*} \mathrm{H}_{\mathrm{P}}$
$\mathrm{H}^{*} \mathrm{~L}$
$\mathrm{L}_{\mathrm{I}}$

$\left[[\text { dato }]_{\mathrm{P}}[\text { NINO-S }]_{\mathrm{P}}\left[c^{\prime} \text { ign-s c'a-ak'itx-eb-s }\right]_{\mathrm{P}}\right]_{\mathrm{I}}$

Fig. 7 shows a multiple focus on the subject and on the direct object. Both the subject and the object have a pitch accent $\left(\mathrm{H}^{*} \mathrm{~L}\right)$. The object forms a final p-phrase together with the verb. The accented effect comes from the unusual height of the p-phrase-initial high tone on c'ign-s 'the book', not visible in the pitch track because of the voiceless affricate starting this word.

(e) Multiple focus congruent pattern
$\mathrm{L} \mathrm{H}^{*} \mathrm{LL}_{\mathrm{P}} \mathrm{L}^{*} \mathrm{H}_{\mathrm{P}}$
$\mathrm{H}^{*} \mathrm{~L}$
$\mathrm{L}_{\mathrm{I}}$
$\left[[D A T O]_{\mathrm{P}} \quad[\text { nino-s }]_{\mathrm{P}} \quad\left[C^{\prime} I G N-S c^{\prime} a-a k^{\prime} i t x-e b-s\right]_{\mathrm{P}}\right]_{\mathrm{I}}$

A final feature of our data remains to be remarked upon. The word orders WO3 $\left(\mathrm{O}_{1} \mathrm{SVO}_{2}\right)$ and WO4 $\left(\mathrm{VSO}_{1} \mathrm{O}_{2}\right)$ had instances of sentence-final narrow focus. All eight instances (distributed over the four sentences) displayed the special low and flat contour $\mathrm{L}^{*} \mathrm{~L}_{\mathrm{I}}$. Additionally, some consonants show more tenseness and aspiration. An example of the final focus $\left(\mathrm{L}^{*} \mathrm{~L}_{\mathrm{I}}\right)$ is shown in (14), with item 2. In (14), a falling pitch accent $\mathrm{H}^{*} \mathrm{~L}$ is realized on the first p-phrase and a rising contour appears in the second p-phrase (Fig. 8).

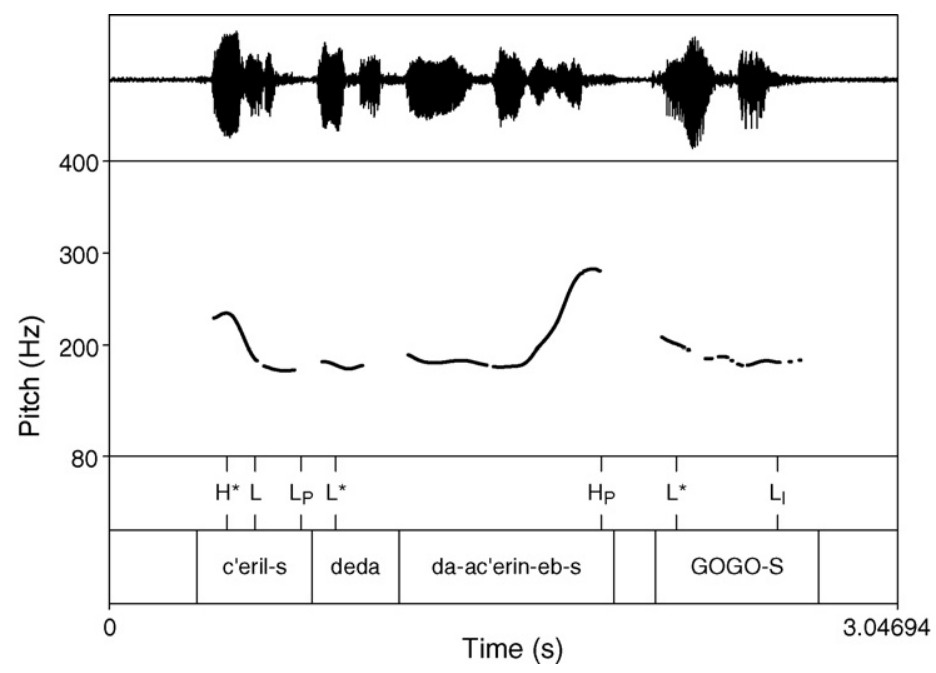

Fig. 8. Item 2 in $\mathrm{WO} 3\left(\mathrm{O}_{1} \mathrm{SVO}_{2}\right)$ : indirect object focus. 


$$
\begin{aligned}
& \begin{array}{lllll}
\mathrm{H}^{*} \mathrm{~L}_{\mathrm{P}} & \mathrm{L}^{*} & \mathrm{H}_{\mathrm{P}} & \mathrm{L}^{*} & \mathrm{~L}_{\mathrm{I}}
\end{array} \\
& {\left[\left[c^{\prime} \text { eril }-s\right]_{\mathrm{P}}[\text { deda da-ac'erin-eb-s }]_{\mathrm{P}} \quad[\text { GOGO-S }]_{\mathrm{P}}\right]_{\mathrm{I}}}
\end{aligned}
$$

letter-DAT mother(NOM) PR(FUT)-(IO.3)CAUS.write-THM-s.3.sG girl-DAT

To sum up, the production experiment revealed the following features of Georgian intonation.

\subsubsection{Comparison between the tonal contours of an all-new sentence and of a narrow focus}

Some regular differences between the realization of words in an all-new sentence and in narrow focus could be identified. First, an all-new sentence mostly contains non-prominent phrases, realized tonally as a sequence $L^{*} H_{P}$, especially when the word order is unmarked.

When the narrowly focused word is initial, it is often realized with a rise-fall $\mathrm{LH}^{*} \mathrm{~L} \mathrm{~L}_{\mathrm{P}}$. However, the rise-fall contour is not bi-uniquely associated with focus, since it also occurs with non-focal constituents (see Fig. 5). In the case of nonfinal focus, the remainder of the sentence has a compressed range. However, at least when the subject or the indirect object is initial (in WO1 $\left(\mathrm{SO}_{2} \mathrm{O}_{1} \mathrm{~V}\right)$ and WO2 $\left(\mathrm{O}_{2} \mathrm{O}_{1} \mathrm{SV}\right)$ ), the remainder of the sentence is fully intonated. In $\mathrm{WO}_{3}\left(\mathrm{O}_{1} \mathrm{SVO}_{2}\right)$, it is the direct object which is initial; in this case our speaker realized a narrowly focused word with a very high pitch accent in the rise-fall, and the remainder of the sentence was more compressed than in the other cases.

A medial narrow focus (neither sentence-initial, nor sentence-final) is realized just with a rise when it is integrated with the following verb (direct object in WO1 $\left(\mathrm{SO}_{2} \mathrm{O}_{1} \mathrm{~V}\right)$, subject focus in WO2 $\left(\mathrm{O}_{2} \mathrm{O}_{1} \mathrm{SV}\right)$ and WO $3\left(\mathrm{O}_{1} \mathrm{SVO}_{2}\right)$ ), but when it is phrased individually, it is again often realized with a rise-fall (subject in $\mathrm{WO} 3\left(\mathrm{O}_{1} \mathrm{SVO}_{2}\right)$ and direct object in WO4 $\left.\left(\mathrm{VSO}_{1} \mathrm{O}_{2}\right)\right)$.

The indirect object in WO1 $\left(\mathrm{SO}_{2} \mathrm{O}_{1} \mathrm{~V}\right)$ is an exception. It is phrased individually, but it is realized just with a steep rise. The reason could be that the subject in this pattern is realized with a rise-fall, maybe because the speaker realized it as a topic, and two full rise-falls in a row are avoided.

A sentence-final focus is realized differently from all the others: it is realized separately, in a p-phrase preceded by a short break, at a low level and with a flat intonation. It was analyzed as $\mathrm{L}^{*} \mathrm{~L}_{\mathrm{I}}$.

In all cases, a crucial property of the narrow focus is what we call emphatic realization: the consonants are realized with intensity, and the words are longer than in the sentences with wide focus. But this property is exaggerated on a final constituent.

In sum, we assume that the correlates of narrow focus are a high pitch accent when non-final and a low pitch accent when final, a clear phrasing except when preverbal, and tenseness as well as intensity in the segments of the focused word.

\subsubsection{Prenuclear part}

Before the high tone of a narrow focus, the full tonal structure is usually present. In verb-final $\mathrm{WO}_{1}\left(\mathrm{SO}_{2} \mathrm{O}_{1} \mathrm{~V}\right)$ for instance, even if the focus is on one of the objects, the subject and the prenuclear object have the same tonal contour as the one they have in the all-new pattern. The same can be said for the WO2 $\left(\mathrm{O}_{2} \mathrm{O}_{1} \mathrm{SV}\right)$ and WO3 $\left(\mathrm{O}_{1} \mathrm{SVO}_{2}\right)$, if the focused word is not final. In WO4 $\left(\mathrm{VSO}_{1} \mathrm{O}_{2}\right)$, there was some compression and restructuring of the prenuclear material, due to the high markedness of this word order. As will be seen in the next section, this pattern was perceived as extremely marginal by the informants, and it would be unwise to draw generalizations on the Georgian intonation from this pattern.

In a sentence with final focus, the prefocal stretch of discourse is clearly compressed. It is also realized more rapidly and without any correlate of the emphasis we find in narrowly focused words.

\subsubsection{Postnuclear part}

In many languages, the material after a narrow focus (postnuclear) is the place where deaccenting is observed. But in our elicited material, it is remarkable how little material is deaccented. Some examples of a sentence-initial narrow focus are illustrated above. But still, the remaining material - except for the verb - is realized with a full tonal pattern. Again, it is difficult to express generalizations on deaccenting from our experimental material, and more studies on Georgian intonation are necessary.

\section{Results}

Sixty subjects participated in the perception experiment and gave 80 judgments each. Of the total of 4800 trials, 455 trials were non-valid (subjects failed to select any value from 1 to 5 within the time window). Some additional 
judgments had to be eliminated due to errors in the combination of question/answer pairs in the DMDX presentation, such that the final data set contained 3797 (79.1\%) valid judgments. The means of judgments reported in the subsequent sections relate to the valid raw data.

Valid judgments have been normalized through transformation into standard scores in order to eliminate individual differences in the way subjects perceived the rating scale (see Cowart, 1997:114). In the final subject/treatment table, missing values (which resulted from the elimination of the non-valid data) have been imputed through a regression analysis carried out on the valid values as predictors for the estimation of the missing ones; standardized residuals have been added to the predicted values in order to correct the reduction of the standard errors which results from the imputation procedure (see Rietveld and Van Hout, 2005:202ff.). All statistical analyses have been conducted on the normalized data after the imputation procedure.

In the subsequent sections, we discuss the interaction between different word orders and prosodic realizations on the means of judgments. The experimental design contains three factors, i.e., context, word order, and prosodic structure (see section 3.2). The effects and the interaction of these factors will be presented in a nested design in the following (sections 4.1-4.5). Our hypotheses in section 3.1 relate to the interaction of prosody and word order for the encoding of particular information structures. The identification of the levels of these factors depends on contextual condition (congruent vs. non-congruent prosody, violations of $\mathrm{XP}_{\mathrm{FOC}} \mathrm{V}$ adjacency). Hence, it suggests itself to nest the data set on the basis of the factor 'context'. In section 4.6 we summarize our major findings and test our hypotheses in the entire data set.

\subsection{All-new}

In an all-new sentence, every constituent is focused, and, as a result, the constraint of $\mathrm{XP}_{\mathrm{FOC}} \mathrm{V}$ adjacency that relates to narrow focus does not apply. The judgments are expected to reflect the word order markedness that results from Areordering, V-fronting, and V-initiality. These expectations are presented in Table 2: based on the assumption that multiple violations will have an additive effect on the acceptability of the presented orders, and the assumption of different strength of the involved violations, the violation profile in Table 2 allows for prediction about the acceptability of the examined orders.

Two prosodic realizations have been examined: The congruent prosodic structure corresponds to a "neutral" intonation, in which no particular prosodic prominence was rendered to any constituent (see the orders lacking underlining in Appendix A). Neutral intonation of this kind is not expected to have an accommodating effect on marked word order. The incongruent prosodic structure was intended for a narrowly focused argument. In other words, only one constituent is prosodically focused, the other ones are prosodically realized as given.

The predictions of Table 2 were borne out, as shown in the obtained results in Fig. 9 (error bars show the standard error of the means at a 0.95 level). A repeated measures analysis of variance revealed a significant main effect for prosodic congruence $\left(F_{1,59}=50.32, p<.001\right)$ and for word $\operatorname{order}\left(F_{1,59}=21.36, p<.001\right)$, as well as a significant interaction between the two factors $\left(F_{1,59}=6.98, p<.01\right)$.

Fig. 9 and subsequent figures are based on the normalized data (see normalization procedure in the previous section). The non-normalized means of the obtained judgments as well as the corresponding normalized values (standard scores) are given in Appendix A. The highest (non-normalized) mean in all parts of the experiment is 4.6 (see Appendix A), i.e., no question/answer pair was given the maximal value 5 by all speakers. We can only speculate about the sources of this variation: first, certain speakers did not use the maximal value at all. Second, particular items may have had negative effects on the intuition of acceptability though they instantiate a fully grammatical syntactic configuration, etc. However, the experimental data do not allow for generalizations concerning the absolute numeric

Table 2

Word order violations in all-new questions

\begin{tabular}{llll}
\hline All-new & STRONG & WEAK & Predicted rank \\
\hline WO1 $\left(\mathrm{SO}_{2} \mathrm{O}_{1} \mathrm{~V}\right)$ & & & 1 \\
WO2 $\left(\mathrm{O}_{2} \mathrm{O}_{1} \mathrm{SV}\right)$ & & A-reordering & 2 \\
WO3 $\left(\mathrm{O}_{1} \mathrm{SVO}_{2}\right)$ & & A-reordering, V-fronting & 3 \\
WO4 $\left(\mathrm{VSO}_{1} \mathrm{O}_{2}\right)$ & V-initial & A-reordering & 4 \\
\hline
\end{tabular}




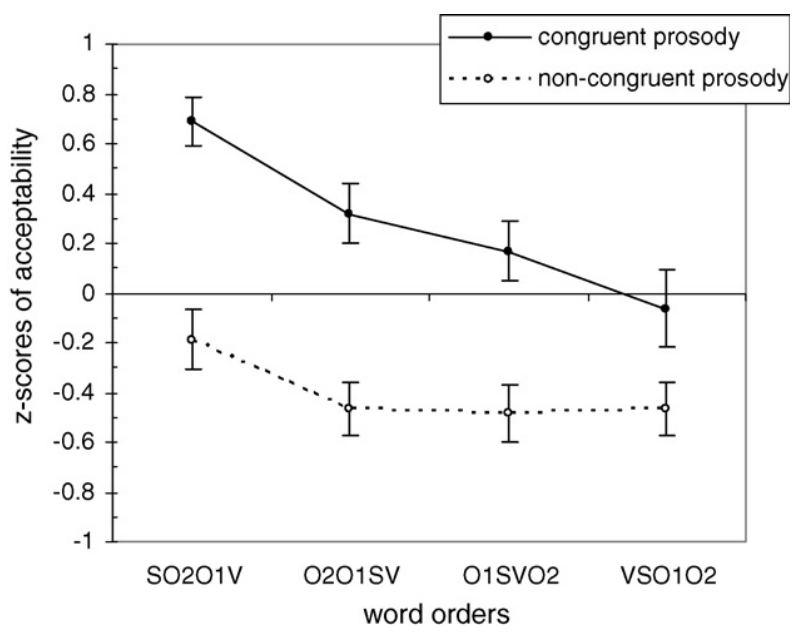

Fig. 9. Judgments in all-new questions.

values. The crucial point is the difference between the observed means that provides evidence for a differential impact of the compared experimental conditions. Following Keller and Alexopoulou (2001:3.5), we assume that two means of acceptability judgments significantly differ whenever their numerical difference is larger than one standard error. In particular, we assume that $x>y$ holds when both $x$ is higher than the higher bound of $y\left(y+\mathrm{SE}_{y}\right)$ and $y$ is lower than the lower bound of $x\left(x-\mathrm{SE}_{x}\right)$.

Prosodically congruent sentences completely confirm the predictions of Table 2. Prosodically non-congruent tokens obtained lower scores, and do not provide evidence for all predicted levels of word order markedness, since only WO1 $\left(\mathrm{SO}_{2} \mathrm{O}_{1} \mathrm{~V}\right)$ reached a distinct level of acceptability compared to the other orders. With respect to the strength of the negative effect of the involved factors, we observe that a strong word order violation, such as the one exemplified through WO4 $\left(\mathrm{VSO}_{1} \mathrm{O}_{2}\right)$, has a comparable effect on acceptability to the non-congruent prosody on the canonical word order WO1 $\left(\mathrm{SO}_{2} \mathrm{O}_{1} \mathrm{~V}\right)$.

\subsection{Subject focus}

In this condition, the context question induces a narrow focus on the subject. The availability of a narrowly focused XP has consequences for the $\mathrm{XP}_{\mathrm{FOC}} \mathrm{V}$ adjacency constraint. Orders that provide a preverbal focused argument that is not left adjacent to the verb exhibit a strong violation, which holds for $\mathrm{WO} 1\left(\mathrm{SO}_{2} \mathrm{O}_{1} \mathrm{~V}\right)$. The further constraint violations are identical to the all-new contexts (see section 4.1) and are summarized in Table 3. The answers to constituent questions are realized with a marked prosodic structure, i.e., a prosody that renders prominent the questioned constituent. As we argued in section 3.1, weak word order violations are expected to be accommodated when a marked prosodic structure places prosodic prominence of the argument that is expected to be focused in the given context.

Fig. 10 presents the obtained results in this contextual condition. A repeated measures analysis of variance showed two significant main effects for prosodic congruence $\left(F_{1,59}=78.84, p<.001\right)$ and for word order $\left(F_{1,59}=24.54\right.$, $p<.001)$. There is no significant interaction between the two factors, which confirms the observation that may be gathered from Fig. 10 that the effects of these factors are cumulatively combined in the result.

Table 3

Word order violations in subject questions

\begin{tabular}{llll}
\hline $\mathrm{S}$ focus & STRONG & WEAK & Predicted rank \\
\hline WO1 $\left(\underline{\mathrm{SO}}_{2} \mathrm{O}_{1} \mathrm{~V}\right)$ & $\mathrm{XP}_{\mathrm{FOC}} \mathrm{V}$ violation & & 3 \\
$\mathrm{WO} 2\left(\mathrm{O}_{2} \mathrm{O}_{1} \underline{\mathrm{S}} \mathrm{V}\right)$ & & A-reordering & 1 \\
WO3 $\left(\mathrm{O}_{1} \underline{\mathrm{S}}_{2}\right)$ & & A-reordering, V-fronting & 2 \\
WO4 $\left(\mathrm{V}^{\mathrm{S}} \mathrm{O}_{1} \mathrm{O}_{2}\right)$ & V-initial & A-reordering & 4 \\
\hline
\end{tabular}




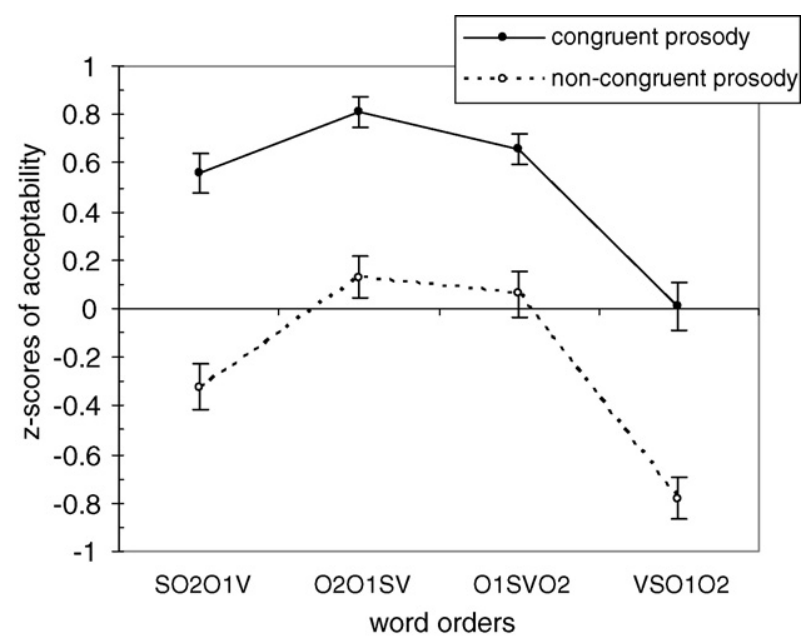

Fig. 10. Judgments in subject questions.

The placement of the focused subject in the position which is left adjacent to the verb increases acceptability, as may be seen in the acceptability means for WO2 $\left(\mathrm{O}_{2} \mathrm{O}_{1} \underline{\mathrm{SV}}\right)$ and WO3 $\left.\left(\mathrm{O}_{1} \underline{\mathrm{SVO}}\right)_{2}\right)$ (compare also with Fig. 9). The difference between WO2 $\left(\mathrm{O}_{2} \mathrm{O}_{1} \underline{\mathrm{SV}}\right)$ and WO3 $\left(\mathrm{O}_{1} \underline{\mathrm{S}} \mathrm{VO}_{2}\right)$ is slightly larger than a standard error (see Appendix A) in the prosodically congruent realizations. Note, furthermore, that $\mathrm{WO} 1\left(\mathrm{SO}_{2} \mathrm{O}_{1} \mathrm{~V}\right)$ obtained very high scores that only slightly differ from WO3 $\left(\mathrm{O}_{1} \underline{S_{V O}}\right)$. This is due to the fact that $\mathrm{SO}_{2} \mathrm{O}_{1} \mathrm{~V}$ is the canonical word order in the language and it retains a high acceptability level across contexts.

The result in Fig. 10 is very informative for our hypothesis concerning strong and weak word order violations. Weak violations, such as the reordering of the arguments in WO2 $\left(\mathrm{O}_{2} \mathrm{O}_{1} \underline{\mathrm{SV}}\right)$ and $\mathrm{WO} 3\left(\mathrm{O}_{1} \underline{\mathrm{S}} \mathrm{VO}_{2}\right)$ are largely ignored when the prosody is appropriate in the context. This does not hold for $\mathrm{WO} 4\left(\mathrm{~V}_{\mathrm{S}} \mathrm{O}_{1} \mathrm{O}_{2}\right)$ that incurs a strong violation. Note that the negative effect of a strong word order violation has the same strength with the effect of a non-congruent prosodic structure on the contextually licit orders WO2 $\left(\underline{\mathrm{O}}_{2} \mathrm{O}_{1} \mathrm{SV}\right)$ and WO3 $\left(\underline{\mathrm{O}}_{1} \mathrm{SVO}_{2}\right)$.

\subsection{Direct object focus}

The next context question licenses a focus feature on the direct object. $\mathrm{XP}_{\mathrm{FOC}} \mathrm{V}$ is satisfied by the canonical order WO1 $\left(\mathrm{SO}_{2} \underline{\mathrm{O}}_{1} \mathrm{~V}\right)$, since in this order the focused constituent is placed immediately before the verb (see Table 4$)$. The orders WO2 $\left(\mathrm{O}_{2} \underline{\mathrm{O}}_{1} \mathrm{SV}\right)$ and WO3 $\left(\underline{\mathrm{O}}_{1} \mathrm{SVO}_{2}\right)$ incur a strong $\mathrm{XP}_{\mathrm{FOC}} \mathrm{V}$ violation in this contextual condition next to the weak violations relating to A-reordering and $\mathrm{V}$-fronting. This constraint does not apply when the verb is fronted as in WO4 ( $\mathrm{VS}_{1} \mathrm{O}_{2}$ ), since postverbal focus is always possible in Georgian (see discussion in section 2.1).

The results are presented in Fig. 11. A repeated measures analysis of variance revealed a significant main effect of prosody $\left(F_{1,59}=47.5, p<.001\right)$ and a significant effect of word order $\left(F_{1,59}=54.03, p<.001\right)$, as well as a significant interaction between word order and prosody $\left(F_{1,59}=6.99, p<.01\right)$.

As expected, WO1 $\left(\mathrm{SO}_{2} \underline{\mathrm{O}}_{1} \mathrm{~V}\right)$ was judged the most appropriate answer to a direct object question. The further orders incur a strong word order violation and obtained a scoring that is at the same level with the scoring of the optimal word order with incongruent prosody as well as the order exhibiting a strong word order violation. If we take

Table 4

Word order violations in direct object questions

\begin{tabular}{llll}
\hline $\mathrm{O}_{1}$ focus & STRONG & WEAK & Predicted rank \\
\hline WO1 $\left(\mathrm{SO}_{2} \underline{\mathrm{O}}_{1} \mathrm{~V}\right)$ & & & 1 \\
$\mathrm{WO} 2\left(\mathrm{O}_{2} \underline{\mathrm{O}}_{1} \mathrm{SV}\right)$ & $\mathrm{XP}_{\mathrm{FOC}} \mathrm{V}$ violation & A-reordering & 2 \\
WO3 $\left(\underline{\mathrm{O}}_{1} \mathrm{SVO}_{2}\right)$ & $\mathrm{XP}$ & A-reordering, V-fronting & 3 \\
$\mathrm{WO} 4\left(\mathrm{VS} \underline{\mathrm{O}}_{1} \mathrm{O}_{2}\right)$ & $\mathrm{V}$-initial & A-reordering & 2 \\
\hline
\end{tabular}




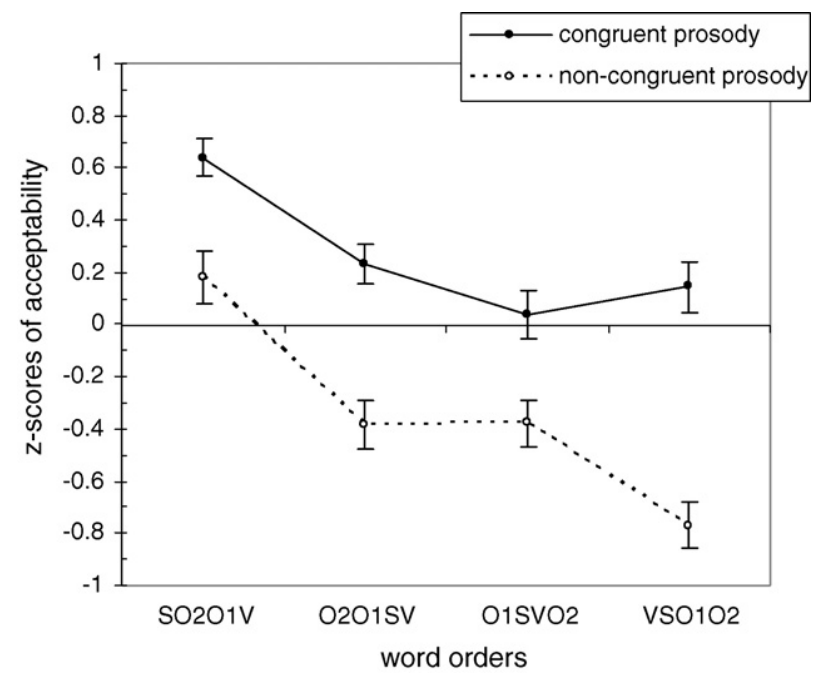

Fig. 11. Judgments in direct object questions.

into account the means differences that are larger than a standard error, the ranking between the three suboptimal orders with congruent prosody is (WO2|WO4) $>$ WO3, which is exactly in line with our predictions in Table 4 . In the prosodically incongruent orders, we observe lower acceptability levels for all orders; the marked word order WO4 $\left(\mathrm{VSO}_{1} \underline{\mathrm{O}}_{2}\right)$ reached a very low acceptability level which is not predicted by Table 4 .

\subsection{Indirect object focus}

None of the examined orders realizes an indirect object focus structure by placing this constituent in the preverbal position. Since the postverbal argument position can also bear focused information, $\mathrm{WO} 3\left(\mathrm{O}_{1} \mathrm{SVO}_{2}\right)$ is predicted to be the best among the candidates though it exhibits two weak word order violations: A-reordering and V-fronting. WO1 $\left(\mathrm{SO}_{2} \mathrm{O}_{1} \mathrm{~V}\right)$ and $\mathrm{WO} 2\left(\underline{\mathrm{O}}_{2} \mathrm{O}_{1} \mathrm{SV}\right)$ incur a strong violation of $\mathrm{XP}_{\mathrm{FOC}} \mathrm{V}$ adjacency. Between the two orders we expect an advantage for $\mathrm{WO} 1\left(\mathrm{SO}_{2} \mathrm{O}_{1} \mathrm{~V}\right)$, reflecting the fact that this is the canonical order. WO4 $\left(\mathrm{VSO}_{1} \underline{\mathrm{O}}_{2}\right)$ displays focus on a postverbal argument, which is possible in Georgian (recall the discussion around Fig. 8 in section 3.3), but V-initiality is not licit in the context of an indirect object question. The violation profile is presented in Table 5.

Similarly with the previous context questions, the prosodic realization is decisive for the judgments. A repeated measures analysis of variance revealed a significant main effect of prosody $\left(F_{1,59}=49.76, p<.001\right)$. The word order factor did not reach significance, nor did the interaction between prosody and word order (Fig. 12).

A comparison of these results with the previous ones reveals that no order reached a high scoring. WO3 $\left(\mathrm{O}_{1} \mathrm{SV}_{2}\right)$ reached the highest scoring, probably due to the fact that all other orders exhibit a strong violation. However, it does not significantly differ from WO1 $\left(\mathrm{SO}_{2} \mathrm{O}_{1} \mathrm{~V}\right)$ which has a general advantage across contexts as the canonical order. The mean of judgments for $\mathrm{WO} 4\left(\mathrm{VSO}_{1} \underline{\mathrm{O}}_{2}\right)$ in the congruent realization is the highest scoring that this order obtained in all experimental conditions; we may speculate that right peripheral placement of the focused constituent has a positive influence on the degree of acceptability, a hypothesis that has to be tested in future research.

Table 5

Word order violations in indirect object questions

\begin{tabular}{llll}
\hline $\mathrm{O}_{2}$ focus & STRONG & WEAK & Predicted rank \\
\hline WO1 $\left(\underline{\mathrm{SO}}_{2} \mathrm{O}_{1} \mathrm{~V}\right)$ & $\mathrm{XP}_{\mathrm{FOC}} \mathrm{V}$ violation & & 2 \\
$\mathrm{WO} 2\left(\underline{\mathrm{O}}_{2} \mathrm{O}_{1} \mathrm{SV}\right)$ & $\mathrm{XP}$ FOC V violation & A-reordering & 3 \\
$\mathrm{WO}\left(\mathrm{O}_{1} \mathrm{SV}_{2}\right)$ & & A-reordering, V-fronting & 1 \\
$\mathrm{WO} 4\left(\mathrm{VSO}_{1} \underline{\mathrm{O}}_{2}\right)$ & V-initial & A-reordering & 3 \\
\hline
\end{tabular}




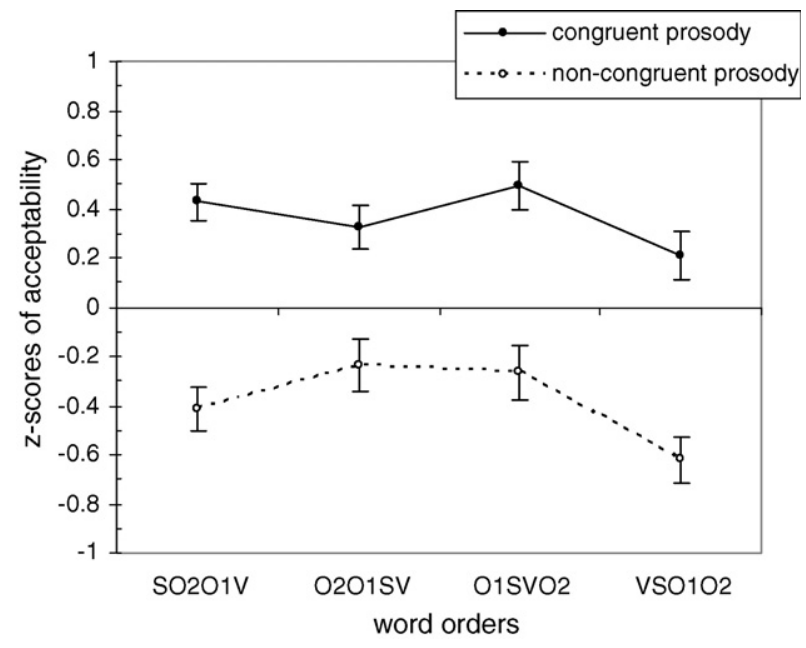

Fig. 12. Judgments in indirect object questions.

In the non-congruent realizations, a low and flat prosody is expected on the narrowly focused indirect object in WO3 $\left(\underline{\mathrm{O}}_{1} \mathrm{SVO}_{2}\right)$, but instead a prosody with an early accent is provided. This may be the reason why acceptability decreased more than in the case of WO2 $\left(\mathrm{O}_{2} \mathrm{O}_{1} \underline{\mathrm{SV}}\right)$ with a late accent.

\subsection{Multiple constituent focus}

In the experiment, multiple constituent questions are combined with single pair answers (see Krifka, 2001; see also evidence from language production in Skopeteas and Féry, 2007). Since the question requests information about the subject and the direct object, we expect that, when either of these arguments is in the preverbal position, no violation of $\mathrm{XP}_{\mathrm{FOC}} \mathrm{V}$ occurs. The expected ranking appears in Table 6 .

The obtained data are presented in Fig. 13. A repeated measures analysis of variance revealed a significant main effect for prosody $\left(F_{1,59}=14.3, p<.001\right)$ and a significant main effect for word order $\left(F_{1,59}=16.87, p<.001\right)$, but no significant interaction between the two factors.

In general, this context induced low judgments in comparison to the previous question types, which may be due to the fact that multiple constituent questions are less common than single constituent questions. Our hypotheses predict the acceptability rank WO1 $>\mathrm{WO} 2>\mathrm{WO} 3>\mathrm{WO} 4$, and the obtained result partly confirms this expectation both in congruent as well as in non-congruent prosodic realizations: (WO1 $\mid \mathrm{WO} 2)>(\mathrm{WO} 3 \mid \mathrm{WO} 4)$. The difference between congruent and non-congruent realizations is smaller in this context, which probably results from the general tendency of the speakers to reject these question/answer pairs.

\subsection{Major findings}

A repeated measures analysis of variance in the overall results revealed a significant main effect of prosodic structure $\left(F_{1,59}=220.11, p<.01\right)$, a significant main effect of word order $\left(F_{1,59}=64.31, p<.001\right)$, and a significant main effect of context $\left(F_{1,59}=6.95, p<.01\right)$. The following sections outline the major generalizations that are supported by our data set.

Table 6

Word order violations in multiple constituent questions

\begin{tabular}{llll}
\hline $\mathrm{S} \& \mathrm{O}_{1}$ focus & STRONG & WEAK & Predicted rank \\
\hline WO1 $\left(\underline{\mathrm{S}} \underline{\mathrm{O}}_{2} \underline{\mathrm{O}}_{1} \mathrm{~V}\right)$ & & & 1 \\
$\mathrm{WO} 2\left(\underline{\mathrm{O}}_{2} \underline{\mathrm{O}}_{1} \underline{\mathrm{S}}\right)$ & & A-reordering & 2 \\
WO3 $\left(\underline{\mathrm{O}}_{1} \underline{\mathrm{S}} \underline{\mathrm{VO}}_{2}\right)$ & A-reordering, V-fronting & 3 \\
WO4 $\left(\underline{\mathrm{SO}}_{1} \mathrm{O}_{2}\right)$ & V-initial & A-reordering & 4 \\
\hline
\end{tabular}




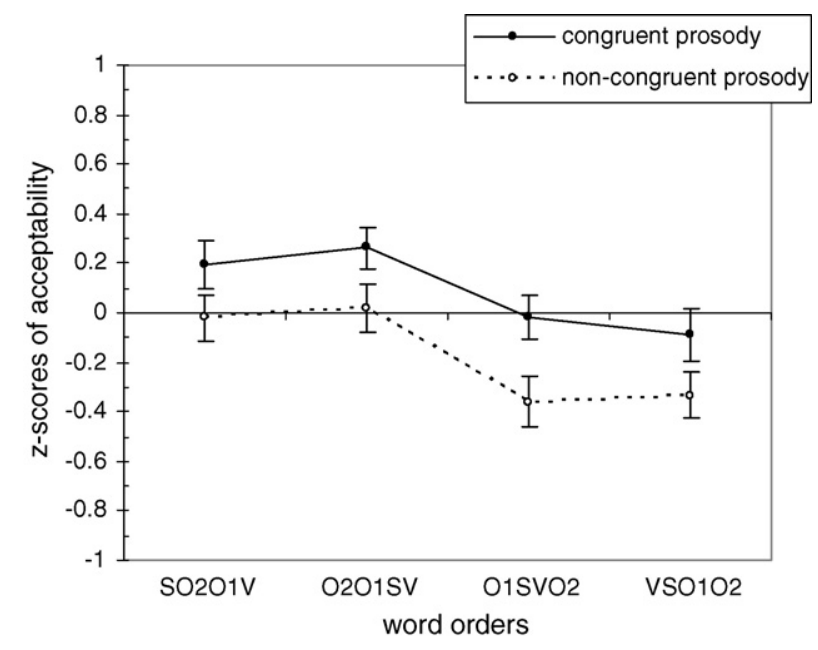

Fig. 13. Judgments in multiple constituent questions.

\subsubsection{May a congruent prosody accommodate word order markedness?}

Our hypothesis concerning the interaction between prosody and syntax is that a marked prosody that is contextually licensed may override the negative effect of weak word order violations such as A-reordering and V-fronting, but not the negative effect of strong word order violations, which are exemplified through V-initiality and violations of $\mathrm{X}_{\mathrm{FOC}} \mathrm{V}$ adjacency in our data set. In the discussion of the previous sections, we observed that this hypothesis explains several aspects of the obtained contrasts.

We take the expressions that do not display any violation at all to provide a baseline that shows the average speakers' reaction, when the question/answer pair is completely felicitous. This baseline is given by the WO1 $\left(\mathrm{SO}_{2} \mathrm{O}_{1} \mathrm{~V}\right)$ in the 'all-new' and the 'direct object focus' contexts; the means of these conditions are given in the left column of Table 7. WO2 $\left(\mathrm{O}_{2} \mathrm{O}_{1} \mathrm{SV}\right)$ and WO3 $\left(\mathrm{O}_{1} \mathrm{SVO}_{2}\right)$ incur weak violations of word order constraints (Areordering in the former, A-reordering and V-fronting in the latter), which have a negative effect on the judgments, as shown in the 'all-new' contexts (line 1 in the middle column of Table 7 presents the mean of both orders). However, when these orders are presented with a marked prosody that is contextually licensed, the effects of word order markedness disappear. This case is exemplified by WO2 $\left(\mathrm{O}_{2} \mathrm{O}_{1} \mathrm{SV}\right)$ in subject questions and by WO3 $\left(\mathrm{O}_{1} \mathrm{SVO}_{2}\right)$ in subject and indirect object questions, in which these orders do not incur any strong violation (line 2 in the middle column of Table 7 presents the mean of these three experimental conditions).

In contrast to weak word order violations, strong word order violations cannot be accommodated by prosody. This contrast is illustrated by the speakers' reactions to $\mathrm{WO} 4\left(\mathrm{VSO}_{1} \mathrm{O}_{2}\right)$ (the right column of Table 7 presents the mean of judgments for WO4: line 1 for the 'all-new' contexts with a neutral prosody, and line 2 for the single constituent questions in which this order is realized with a marked congruent prosody). ${ }^{4}$

Table 7

Prosodic markedness and word order constraints

\begin{tabular}{|c|c|c|c|c|c|c|}
\hline & \multicolumn{2}{|c|}{ No violation } & \multicolumn{2}{|c|}{ Weak violation } & \multicolumn{2}{|c|}{ Strong violation } \\
\hline & Means & S.E. & Means & S.E. & Means & S.E. \\
\hline Neutral prosody & 0.69 & \pm 0.09 & 0.24 & \pm 0.09 & -0.06 & \pm 0.15 \\
\hline Marked prosody & 0.63 & \pm 0.07 & 0.66 & \pm 0.05 & 0.12 & \pm 0.07 \\
\hline
\end{tabular}

\footnotetext{
${ }^{4}$ The data from multiple constituent questions are ignored in these measurements, since they involve an overall negative effect that depends on this type of context.
} 
Table 8

Prosodic congruence and word order constraints

\begin{tabular}{|c|c|c|c|c|c|c|}
\hline & \multicolumn{2}{|c|}{ No violation } & \multicolumn{2}{|c|}{ Weak violation } & \multicolumn{2}{|c|}{ Strong violation } \\
\hline & Means & S.E. & Means & S.E. & Means & S.E. \\
\hline Congruent prosody & 0.66 & \pm 0.06 & 0.65 & \pm 0.05 & 0.21 & \pm 0.04 \\
\hline Incongruent prosody & -0.01 & \pm 0.07 & -0.02 & \pm 0.06 & -0.48 & \pm 0.05 \\
\hline
\end{tabular}

A repeated measures analysis of variance on the two factors presented in Table 7 revealed a significant main effect for word order violations $\left(F_{1,59}=43.91, p<.001\right)$. The factor prosodic markedness does not have a significant main effect, which is expected since both neutral and marked prosodic realizations are congruent to the context and are not expected to differ in acceptability. The interaction between the two factors is not significant.

Taken that the acceptability of the canonical word order in all-new contexts is a baseline for the estimation of felicitous question/answer pairs, we observe that the mean of the canonical word order with a contextually licensed marked prosody does not significantly differs. The critical evidence for our hypothesis relates to the expressions with a weak word order violation: the acceptability of these orders differs significantly from the baseline $\left(t_{59}=4.81, p<0.001\right)$, when these orders are presented in a neutral context with neutral prosody, but it does not differ significantly when they are presented with a marked prosody that is licensed by the context (and provided that they do not incur a $\mathrm{XP}_{\mathrm{FOC}} \mathrm{V}$ violation). In contrast, the speakers' reaction to strong word order violations is significantly lower than the baseline, both in all-new contexts with unmarked prosody $\left(t_{59}=5.15, p<0.001\right)$, as well as in the context of constituent questions with congruent prosody $\left(t_{59}=5.77, p<0.001\right)$. Finally, the difference between the means of strong word order violations with either neutral or marked prosody did not reach significance.

This data confirm our hypothesis that a marked prosodic structure that is congruent with the context may accommodate the negative effect of weak word order violations on contextual felicity but not the negative effect of strong word order violations.

\subsubsection{Do prosodic and syntactic infelicities have a cumulative effect?}

The effects of prosodic structure are very consistent across conditions. Speakers judged incongruent intonation on average 0.88 points lower in the 1-5 scale (non-normalized values). Highly significant main effects for prosodic congruence were obtained in all contexts. We observed that the interaction between prosody and word order did not reach significance in subject questions (see section 4.2), indirect object questions (see section 4.4), and multiple constituent questions (see section 4.5). The absence of interaction reflects the fact that non-congruent prosody had an additive negative effect of more or less the same size in most cases.

The interaction of word order and prosody in the entire data set is obtained from the comparison of the three levels of word order violations that we assumed in the previous section: (a) no violation: $\mathrm{WO} 1\left(\mathrm{SO}_{2} \mathrm{O}_{1} \mathrm{~V}\right)$ in the 'all-new' and the 'direct object focus', (b) weak word order violation, containing WO2 $\left(\mathrm{O}_{2} \mathrm{O}_{1} \mathrm{SV}\right)$ and $\mathrm{WO} 3\left(\mathrm{O}_{1} \mathrm{SVO}_{2}\right)$ in the contexts in which these orders only incur weak word order violations, and (c) strong word order violation, containing $\mathrm{WO} 4\left(\mathrm{VSO}_{1} \mathrm{O}_{2}\right)$ as well as the further orders in contexts in which they incur an $\mathrm{XP}_{\mathrm{FOC}} \mathrm{V}$ violation.

These means are summarized in Table 8 . A repeated measures analysis of variance reveals a significant main effect for prosody $\left(F_{1,59}=77.03, p<.001\right)$ and a significant main effect for word order constraints $\left(F_{1,59}=74.14\right.$, $p<.001)$. The interaction between prosody and word order is not significant, which is in line with the observation that a non-congruent prosody has a consistent additive effect (of 0.6 points in the normalized data) to the felicity of the syntactic properties of the expression at issue.

\subsubsection{Is there an asymmetry in the acceptability of prenuclear and postnuclear accents?}

The negative effect of a non-congruent prosodic realization may differ depending on accent placement. Based on previous studies (see section 3.1), we hypothesized that a late non-congruent pitch accent may have a stronger negative effect on the acceptability judgments that an early non-congruent accent. Two non-congruent answers in each question display an earlier prosodically prominent constituent than expected, and two answers display a prosodically prominent constituent later than expected. 
Table 9

Difference between congruent and non-congruent prosodic realizations

\begin{tabular}{|c|c|c|c|c|c|c|}
\hline & \multicolumn{2}{|c|}{ Subject questions } & \multicolumn{2}{|c|}{ Direct object questions } & \multicolumn{2}{|c|}{ Indirect object questions } \\
\hline & Order & Difference & Order & Difference & Order & Difference \\
\hline \multirow[t]{2}{*}{ Early accent } & $\underline{\mathrm{O}}_{2} \mathrm{O}_{1} \mathrm{SV}$ & 0.69 & $\underline{\mathrm{S}} \mathrm{O}_{2} \mathrm{O}_{1} \mathrm{~V}$ & 0.45 & $\underline{\mathrm{O}}_{1} \mathrm{SVO}_{2}$ & 0.75 \\
\hline & $\underline{\underline{\mathrm{O}}}_{1} \mathrm{SVO}_{2}$ & 0.61 & $\underline{\mathrm{O}}_{2} \mathrm{O}_{1} \mathrm{SV}$ & 0.61 & $\overline{\mathrm{V}} \underline{\mathrm{S}} \mathrm{O}_{1} \mathrm{O}_{2}$ & 0.83 \\
\hline \multirow[t]{2}{*}{ Late accent } & $\mathrm{SO}_{2} \mathrm{O}_{1} \mathrm{~V}$ & 0.87 & $\mathrm{O}_{1} \underline{\mathrm{S}_{\mathrm{VO}}}$ & 0.4 & $\mathrm{SO}_{2} \underline{\mathrm{O}}_{1} \mathrm{~V}$ & 0.84 \\
\hline & $\overline{\mathrm{VS}} \underline{\mathrm{O}}_{1} \mathrm{O}_{2}$ & 0.79 & $\mathrm{VSO}_{1} \underline{\mathrm{O}}_{2}$ & 0.9 & $\mathrm{O}_{2} \mathrm{O}_{1} \underline{\mathrm{S}} \mathrm{V}$ & 0.55 \\
\hline
\end{tabular}

Table 9 summarizes the differences between congruent and non-congruent prosodic realizations in single constituent questions. In line with our hypothesis, the size of the negative effect of realizations with a late accent is greater than the negative effect of an early accent in the context of subject questions. ${ }^{5}$ However, in the other contexts, our hypothesis is not borne out, since realizations with late accents $\left(\mathrm{O}_{1} \underline{\mathrm{S}} \mathrm{VO}_{2}\right.$ in direct object questions and $\mathrm{O}_{2} \mathrm{O}_{1} \underline{\mathrm{S} V}$ in indirect object questions) trigger the smallest negative effects. Hence, accent placement does not seem to play a noticeable role in our data set, probably due to the fact that prosodic prominence was realized with particular clarity in the stimulus material. We assume that speakers easily recognized the prosodically prominent part of the utterance and their judgments reflect their negative reaction to the mismatch without being particularly influenced by the properties of the accent placement.

\subsubsection{Does case inversion interact with information structure?}

The results from the manipulation of case marking show no interaction between case inversion and information structure. As mentioned above, all our items were implemented in two different aspects in order to counterbalance effects of the different case marking patterns on information structure (see example 10 in section 3.2). The background of this decision in the experimental design is that it is pointed out that case marking in Georgian corresponds to differences in the discourse properties of agents and patients (see Asatiani, 2007a; Harris, 1985:295-300). In particular, the nominative marking of patients in the perfect tense reflects the fact that this constituent is "discourse prominent" in this aspect/mood (note that Georgian perfects have an evidential function).

We assume that the discourse prominent constituent is the constituent the answer is about. In the question/ answer pairs that we examined, this assumption implies that the answer is more felicitous when the given argument, i.e., the argument introduced in the question, bears nominative case. In subject focus questions, the nominative marked direct object (perfect tense) should be more felicitous than the dative marked direct object (future tense). This prediction is not borne out: a repeated measures analysis of variance revealed that there is no significant main effect of case marking in this context ( $p<.92$; word order has a significant main effect, see section 4.3). The opposite prediction may be tested in direct object questions. In this context, the subject is expected to obtain higher scorings when it bears nominative case, i.e., in the future tense. A repeated measures analysis of variance revealed again that there is no significant main effect of case marking ( $p<.17$; word order has a significant main effect, see section 4.4).

Hence, our data show that both nominative and dative arguments may serve as equally felicitous hosts for either a focused or a backgrounded constituent. This result implies that case marking is not sensitive to information structure in question/answer pairs. However, this finding should not be over-generalized. Case marking depends on the tense properties of the examined Georgian verbs. Since the answer is expected to have the same tense properties with the question, it is not expected that the preference for a particular case marking of discourse prominent arguments will affect the choice of verb inflection in a question/answer pair. This conclusion does not exclude other types of possible interaction between tense and discourse state of the arguments that are not tested in this context: e.g., inverse marking occurs in the perfect tenses, which have evidential function in Georgian, and it may be that epistemic uses of verbs occur less frequently with an agent constituent (see Harris, 1981; Blevins, 2005). Future research will hopefully examine such correlations that may provide empirical evidence for the relation between case inversion and information structure.

\footnotetext{
${ }^{5}$ We assume that what we called prosodic levelling above, a low pitch accent noted $\mathrm{L}^{*}$, is recognized as the correlate of a narrow focus.
} 


\section{Conclusion}

This paper has presented the results of a perception experiment investigating the interaction of word order and intonation in Georgian, a language with a rich tonal structure and free word order. Most of the hypotheses, formulated on the basis of what is known about this language, could be confirmed.

We examined four major phenomena of Georgian word order: V-fronting, argument reordering, left adjacency of focused XPs to the verb, and V-movement to the sentence initial position. Based on the observations in previous works (Apridonidze, 1986; Asatiani, 2007a; Harris, 1981, 1993; McGinnis, 1997; Skopeteas and Fanselow, in pressb; Tuite, 1998), we assumed that the two former operations are 'optional' in the sense that they are chosen in order to satisfy discourse related preferences that affect the linearization, but do not display the properties of movement that targets particular positions that are associated with discrete semantic or pragmatic functions. The latter two operations are restrictive: a violation of the preference for left adjacency of focused XPs to the verb results in loss of acceptability, and placement of the verb in the sentence initial position is contextually restricted to a particular type of contexts.

Our experimental evidence has shown that violations of the former type are completely ignored when these expressions are presented with a marked prosodic structure licensed by the context. Violations of the latter type result in loss of acceptability that cannot be overridden by prosody.

Furthermore, the experimental results have shown that a non-congruent prosody has a very robust negative effect on acceptability. Prosodic infelicities had an additive effect to word order infelicities, showing that the felicity of an expression in the context is the product of its syntactic and prosodic properties.

To conclude, previous studies have shown that prosody is a strong indicator for the focus properties of the utterance in intonational languages. Whenever the prosodic properties do not correspond the contextual expectations, a clear negative reaction of the speakers is induced. In languages with free word order, word order is sensitive to information structure too, but word order infelicities may be overridden by an appropriate prosodic structure. This observation may lead to the conclusion that prosodic constraints outrank syntactic constraints in the encoding of information structure.

\section{Acknowledgments}

This paper is a product of the project "Typology of Information Structure," which is part of the SFB 632 "Information Structure" at the University of Potsdam and Humboldt University Berlin (sponsored by the DFG). An important part of the observations about word order comes from common work with Gisbert Fanselow on Georgian syntax. During the preparation of the final version of the paper we profited from the substantial comments of three anonymous reviewers. Special thanks are due to Shorena Bartaia, Anna Tsutkerashvili, and Nutsa Tsereteli, who contributed to the development and execution of our experiments and Kirsten Bock for her comments on a pre-final draft. Many thanks also to Ani Asatiani, Nana Chidrashvili, and Natja Dundua for their assistance in the execution of the experiments in Tbilisi.

\section{Appendix A. Means of judgments and standard scores}

\begin{tabular}{|c|c|c|c|c|c|c|}
\hline \multirow[t]{2}{*}{ Focus } & \multirow[t]{2}{*}{ Prosody } & \multirow[t]{2}{*}{ Order } & \multirow{2}{*}{$\begin{array}{l}\text { Judgments } \\
\text { Mean }\end{array}$} & \multicolumn{3}{|c|}{ Standard scores } \\
\hline & & & & Mean & S.E. ${ }^{a}$ & S.D. \\
\hline \multirow[t]{8}{*}{ All } & Congruent & $\mathrm{SO}_{2} \mathrm{O}_{1} \mathrm{~V}$ & 4.5 & 0.69 & 0.09 & 0.75 \\
\hline & & $\mathrm{O}_{2} \mathrm{O}_{1} \mathrm{SV}$ & 4 & 0.31 & 0.12 & 0.93 \\
\hline & & $\mathrm{O}_{1} \mathrm{SVO}_{2}$ & 3.7 & 0.16 & 0.12 & 0.93 \\
\hline & & $\mathrm{VSO}_{1} \mathrm{O}_{2}$ & 3.4 & -0.06 & 0.15 & 1.18 \\
\hline & Non-congruent & $\mathrm{SO}_{2} \mathrm{O}_{1} \mathrm{~V}$ & 3.1 & -0.18 & 0.11 & 0.89 \\
\hline & & $\underline{\mathrm{O}}_{2} \mathrm{O}_{1} \mathrm{SV}$ & 2.7 & -0.46 & 0.11 & 0.81 \\
\hline & & $\mathrm{O}_{1} \mathrm{SVO}_{2}$ & 2.7 & -0.48 & 0.11 & 0.91 \\
\hline & & $\operatorname{VSO}_{1} \underline{\overline{\mathrm{O}}}_{2}$ & 2.8 & -0.46 & 0.11 & 0.85 \\
\hline
\end{tabular}


Appendix A (Continued)

\begin{tabular}{|c|c|c|c|c|c|c|}
\hline \multirow[t]{2}{*}{ Focus } & \multirow[t]{2}{*}{ Prosody } & \multirow[t]{2}{*}{ Order } & \multirow{2}{*}{$\begin{array}{l}\text { Judgments } \\
\text { Mean }\end{array}$} & \multicolumn{3}{|c|}{ Standard scores } \\
\hline & & & & Mean & S.E. ${ }^{a}$ & S.D. \\
\hline \multirow[t]{8}{*}{ Subject } & \multirow[t]{4}{*}{ Congruent } & $\underline{\mathrm{S}} \mathrm{O}_{2} \mathrm{O}_{1} \mathrm{~V}$ & 4.2 & 0.55 & 0.08 & 0.62 \\
\hline & & $\mathrm{O}_{2} \mathrm{O}_{1} \underline{\mathrm{S}} \mathrm{V}$ & 4.6 & 0.81 & 0.06 & 0.48 \\
\hline & & $\mathrm{O}_{1} \underline{\mathrm{SVO}}_{2}$ & 4.4 & 0.66 & 0.06 & 0.49 \\
\hline & & $\mathrm{V} \underline{\mathrm{S}} \mathrm{O}_{1} \mathrm{O}_{2}$ & 3.4 & 0.01 & 0.09 & 0.74 \\
\hline & \multirow[t]{4}{*}{ Non-congruent } & $\mathrm{SO}_{2} \mathrm{O}_{1} \mathrm{~V}$ & 3 & -0.32 & 0.09 & 0.71 \\
\hline & & $\underline{\mathrm{O}}_{2} \mathrm{O}_{1} \mathrm{SV}$ & 3.6 & 0.12 & 0.08 & 0.66 \\
\hline & & $\underline{\underline{\mathrm{O}}}_{1} \mathrm{SVO}_{2}$ & 3.4 & 0.05 & 0.09 & 0.71 \\
\hline & & $\mathrm{VS} \underline{\mathrm{O}}_{1} \mathrm{O}_{2}$ & 2.2 & -0.78 & 0.08 & 0.65 \\
\hline \multirow[t]{8}{*}{ Direct object } & \multirow[t]{4}{*}{ Congruent } & $\mathrm{SO}_{2} \underline{\mathrm{O}}_{1} \mathrm{~V}$ & 4.4 & 0.63 & 0.07 & 0.53 \\
\hline & & $\mathrm{O}_{2} \underline{\mathrm{O}}_{1} \mathrm{SV}$ & 3.8 & 0.23 & 0.07 & 0.58 \\
\hline & & $\underline{\mathrm{O}}_{1} \mathrm{SVO}_{2}$ & 3.4 & 0.03 & 0.09 & 0.72 \\
\hline & & $\overline{\mathrm{VSS}} \underline{\mathrm{O}}_{1} \mathrm{O}_{2}$ & 3.7 & 0.14 & 0.09 & 0.75 \\
\hline & \multirow[t]{4}{*}{ Non-congruent } & $\underline{\mathrm{S}} \mathrm{O}_{2} \mathrm{O}_{1} \mathrm{~V}$ & 3.6 & 0.18 & 0.09 & 0.75 \\
\hline & & $\underline{\mathrm{O}}_{2} \mathrm{O}_{1} \mathrm{SV}$ & 2.9 & -0.38 & 0.09 & 0.71 \\
\hline & & $\mathrm{O}_{1} \underline{\mathrm{SVO}_{2}}$ & 2.8 & -0.37 & 0.08 & 0.69 \\
\hline & & $\mathrm{VSO}_{1} \underline{\mathrm{O}}_{2}$ & 2.3 & -0.76 & 0.08 & 0.68 \\
\hline \multirow[t]{8}{*}{ Indirect object } & \multirow[t]{4}{*}{ Congruent } & $\mathrm{SO}_{2} \mathrm{O}_{1} \mathrm{~V}$ & 4.1 & 0.43 & 0.07 & 0.59 \\
\hline & & $\underline{\mathrm{O}}_{2} \mathrm{O}_{1} \mathrm{SV}$ & 3.9 & 0.32 & 0.08 & 0.65 \\
\hline & & $\mathrm{O}_{1} \mathrm{SVO}_{2}$ & 4.2 & 0.49 & 0.09 & 0.76 \\
\hline & & $\mathrm{VSO}_{1} \underline{\mathrm{O}}_{2}$ & 3.8 & 0.21 & 0.09 & 0.74 \\
\hline & \multirow[t]{4}{*}{ Non-congruent } & $\mathrm{SO}_{2} \underline{\mathrm{O}}_{1} \mathrm{~V}$ & 2.8 & -0.41 & 0.08 & 0.68 \\
\hline & & $\mathrm{O}_{2} \mathrm{O}_{1} \underline{\mathrm{S}} \mathrm{V}$ & 3 & -0.23 & 0.11 & 0.82 \\
\hline & & $\underline{\mathrm{O}}_{1} \mathrm{SVO}_{2}$ & 3 & -0.26 & 0.11 & 0.87 \\
\hline & & $\mathrm{VS} \mathrm{O}_{1} \mathrm{O}_{2}$ & 2.5 & -0.62 & 0.09 & 0.72 \\
\hline \multirow[t]{8}{*}{ Multiple } & \multirow[t]{4}{*}{ Congruent } & $\underline{\mathrm{S}} \mathrm{O}_{2} \underline{\mathrm{O}}_{1} \mathrm{~V}$ & 3.7 & 0.19 & 0.09 & 0.73 \\
\hline & & $\mathrm{O}_{2} \underline{\mathrm{O}}_{1} \underline{\mathrm{S}} \mathrm{V}$ & 3.8 & 0.26 & 0.08 & 0.67 \\
\hline & & $\underline{\mathrm{O}}_{1} \underline{\mathrm{SVO}_{2}}$ & 3.4 & -0.01 & 0.08 & 0.68 \\
\hline & & $\mathrm{VSO}_{1} \mathrm{O}_{2}$ & 3.3 & -0.09 & 0.11 & 0.81 \\
\hline & \multirow[t]{4}{*}{ Non-congruent } & $\mathrm{SO}_{2} \mathrm{O}_{1} \mathrm{~V}$ & 3.4 & -0.02 & 0.09 & 0.71 \\
\hline & & $\underline{\mathrm{O}}_{2} \mathrm{O}_{1} \mathrm{SV}$ & 3.5 & 0.01 & 0.09 & 0.76 \\
\hline & & $\overline{\mathrm{O}}_{1} \mathrm{SVO}_{2}$ & 2.8 & -0.35 & 0.11 & 0.77 \\
\hline & & $\mathrm{VSO}_{1} \overline{\mathrm{O}}_{2}$ & 2.9 & -0.33 & 0.09 & 0.73 \\
\hline
\end{tabular}

\footnotetext{
${ }^{a}$ S.E.: standard error; S.D.: standard deviation.
}

\section{References}

Alkhazishvili, A., 1959. porjadok slov i intonacija v prostom povestvovateljnom predlojenii gruzin skogo jazyka [Word order and intonation in simple extended sentences in Georgian]. Phonetics (Moscow) I, 367-414.

Alter, K., Mleinek, I., Umbach, C., Rohe, T., 2001. Kontrastprosodie in Sprachproduktion und -perzeption. In: Steube, A., Umbach, C. (Eds.), Kontrast: lexikalisch, semantisch, phonologisch. Linguistische Arbeitsberichte, vol. 77. Institut für Linguistik, Universität Leipzig, pp. 59-81. Amiridze, N., 2006. Reflexivization Strategies in Georgian. Ph. D. dissertation, University of Utrecht. LOT, Utrecht.

Anderson, S.R., 1984. On representations in morphology: case, agreement, and inversion in Georgian. Natural Language and Linguistic Theory 2 , $157-218$.

Apridonidze, Sh., 1986. sit'q'vatganlageba axal kartulši [Word order in modern Georgian]. Mecniereba, Tbilisi.

Aronson, H.I., 1982. Georgian: A Reading Grammar. Slavica, Chicago.

Asatiani, R., 1982. mart'ivi c'inadadebis t'ip'ologiuri analizi (tanamedrove kartuli salit'erat'uro enis masalaze [The typological analysis of a simple sentence (on the data of modern literary Georgian)]. Mecniereba, Tbilisi.

Asatiani, R., 2007a. The main devices of foregrounding in the information structure of Georgian sentences. In: Ten Cate, B., Zeevat, H. (Eds.), Proceedings of the Tbilisi Symposium on Language, Logic and Computation 2005. Springer, Amsterdam, pp. 21-30. 
Asatiani, R., 2007b. Georgian. In: Skopeteas, S., Hellmuth, S., Fanselow, G., Féry, C. (Eds.), The Expression of Information Structure: The Interaction of Syntax and Phonology in Cross-Linguistic Perspective. Mouton De Gruyter, Berlin.

Blevins, J. 2005, Thematic inversion in Georgian. Ms., University of Cambridge.

Boeder, W., 1989. Verbal person marking, noun phrase and word order in Georgian. In: Marácz, L., Muysken, P. (Eds.), Configurationality: The Typology of Asymmetries. Foris, Dordrecht, pp. 159-184.

Boeder, W., 2005. The South Caucasian languages. Lingua 115, 5-89.

Büring, D., 2001. Let's phrase it! - Focus, word order, and prosodic phrasing in German double object constructions In: Müller, G., Sternefeld, W. (Eds.), Competition in Syntax. Benjamins, Amsterdam, pp. 101-137.

Bush, R., 1999. Georgian Yes-No Question Intonation. Phonology at Santa Cruz, vol. 6. UC Santa Cruz, Santa Cruz CA, pp. 1-11.

Cowart, W., 1997. Experimental Syntax: Applying Objective Methods to Sentence Judgments. Sage Publications, Thousand Oaks, CA.

Davitiani, A., 1973. kartuli enis sint'aksi [Syntax of the Georgian language]. Ganatleba, Tbilisi.

Féry, C., Samek-Lodovici, V., 2006. Focus projection and prosodic prominence in nested foci. Language 82 (1), 131-150.

Féry, C., Skopeteas, S., 2008. Prosodic structure of Georgian: evidence from language production.

Féry, C., Stoel, R., 2006. Gradient perception of intonation. In: Fanselow, G., Féry, C., Schlesewsky, M., Vogel, R. (Eds.), Gradience in Grammar: Generative Perspectives. Oxford University Press, Oxford, pp. 145-166.

Golston, C., 1995. Syntax outranks phonology: evidence from Ancient Greek. Phonology 12 (3), 343-368.

Gussenhoven, C., 1983. Testing the reality of focus domains. Language and Speech 26, 61-80.

Harford, C., Demuth, K., 1999. Prosody outranks syntax: an optimality approach to subject inversion in Bantu relatives. Linguistic Analysis 29 (12), 47-68.

Harris, A.C., 1981. Georgian Syntax: A Study in Relational Grammar. Cambridge University Press, Cambridge.

Harris, A.C., 1985. Diachronic Syntax: The Kartvelian Case. Academic Press, New York.

Harris, A.C., 1993. Georgian. In: Jacobs, J., von Stechow, A., Sternefeld, W., Vennemann, Th. (Eds.), Syntax: An International Handbook of Contemporary Research. De Gruyter, Berlin/New York, pp. 1377-1397.

Harris, A.C., 2000. Word order harmonies and word order change in Georgian. In: Sornicola, R., Poppe, E., Haley, A. (Eds.), Stability, Variation, and Change of Word-Order Patterns over Time. Benjamins, Amsterdam/Philadelphia, pp. 133-163.

Hewitt, B.G., 1995. Georgian: A Structural Reference Grammar. Benjamins, Amsterdam/Philadelphia.

Jun, S.-A., Vicenik, Ch., Lofstedt, I., 2007. Intonational Phonology of Georgian. PowerPoint Presentation given at the Workshop on Intonational phonology: Understudied or Fieldwork Languages. Saarbrücken, Germany.

Keller, F., Alexopoulou, Th., 2001. Phonology competes with syntax: Experimental evidence for the interaction of word order and accent placement in the realization of information structure. Cognition 79 (3), 301-371.

Kiziria, N., 1987. salit'erat'uro kartulis int'onaciis sak'itxebi [Issues of intonation of literary Georgian]. Mecniereba, Tbilisi.

Krifka, M., 2001. For a structured meaning account of questions and answers. In: Féry, C., Sternefeld, W. (Eds.), Audiatur Vox Sapientiae: A Festschrift for Arnim von Stechow, Studia grammatical, vol. 52. Akademie Verlag, Berlin, pp. 287-319.

Kvačadze, L., 1996. tanamedrove kartuli enis sint'aksi [Syntax of the contemporary Georgian language] (the fourth revised edition). Rubikoni, Tbilisi.

McGinnis, M., 1997. Case and locality in L-Syntax: evidence from Georgian. In: Harley, H. (Ed.), The UPenn/MIT Roundtable on Argument Structure and Aspect. MITWPL 32.

McGinnis, M., 1999. A-scrambling exists! In: Minnick, Michelle, Han, Na-Rae, (Eds.), Proceedings of the 23th Annual Penn Linguistics Colloquium. Penn Working Papers in Linguistics, Department of Linguistics, University of Pennsylvania.

McGinnis, M., 2004. Lethal ambiguity. Linguistic Inquiry 35 (1), 47-95.

Müller, G., 2007. Frageintonation im Georgischen. Master's thesis. University of Cologne.

Nash, L., 1995. Portée argumentale at marquage casuel dans les langues SOV et dans les langues ergatives: l'exemple du géorgien. Ph.D., Université de Paris VIII.

Počxua, B., 1962. sit'q'vata rigi kartulši [Word order in Georgian]. Ibero-Caucasian Linguistics (Tbilisi) 13, 109-125.

Rietveld, T., Van Hout, R., 2005. Statistics in Language Research: Analysis of Variance. Mouton De Gruyter, Berlin/New York.

Selkirk, E., 1984. Phonology and Syntax: The Relation between Sound and Structure. MIT Press, Cambridge, Mass.

Skopeteas, S., Fanselow, G. Effects of givenness and constraints on free word order. In: Zimmermann, M., Féry, C. (Eds.), Information Structure from Different Perspectives. Oxford University Press, Oxford, in press-a.

Skopeteas, S., Fanselow, G. Focus in Georgian and the expression of contrast. In: Cook, Philippa, Repp, Sophie (Eds.), Special Issue on Contrast, Lingua, in press-b.

Skopeteas, S., Féry, C., 2007. Contrastive topics in pairing answers: a cross-linguistic production study. In: Featherston, S., Sternefeld, W. (Eds.), Linguistic Evidence, vol. 2. Mouton de Gruyter, Berlin.

Skopeteas, S., Fanselow, G., Asatiani, R., 2008. Case Inversion in Georgian. Ms., University of Potsdam.

Tevdoradze, I., 1978. kartuli enis p'rosodiis sak'itxebi [Issues of prosody of the Georgian language]. Tbilisi State University Press, Tbilisi.

Truckenbrodt, H., 1999. On the relation between syntactic phrases and phonological phrases. Linguistic Inquiry 30, $219-255$.

Tuite, K., 1998. Kartvelian Morphosyntax: Number, Agreement, and Morphosyntactic Orientation in the South Caucasian Languages. Lincom Europa, Munich.

Vogt, H., 1971. Grammaire de la langue géorgienne. Universitaetsvorlaget, Oslo.

Zec, D., Inkelas, Sh., 1990. Prosodically constrained syntax. In: Inkelas, S., Zec, D. (Eds.), The Phonology-Syntax Connection. Center for the Study of Language and Information, The University of Chicago Press, Chicago, pp. 365-378.

Zhghenti, S., 1963. kartuli enis rit'mik'ul-melodik'uri st'ruk't'ura [Rhythmic and melodic structure of the Georgian language]. Codna, Tbilisi. 


\section{Glosses}

2: 2nd person

3: 3rd person

ADV: adverbializer

CAUS: causative

DAT: dative

FUT: future

GEN: genitive

INVO: inverted object

INVs: inverted subject

IO: indirect object (person affix)

NOM: nominative

PL: plural

PRF: perfect

PRS: present

PR: preverb

PV: preradical vowel

s: subject (person affix)

SG: singular

THM: thematic suffix 